\title{
Pharmacological Treatment of Vascular Dementia: A Molecular Mechanism Perspective
}

\author{
Huang Kuang ${ }^{1}$, Zhi-Feng Zhou ${ }^{1}$, Yu-Ge Zhu ${ }^{1}$, Zhi-Kai Wan ${ }^{1}$, Mei-Wen Yang ${ }^{2}$, Fen-Fang Hong ${ }^{3 *}$, \\ Shu-Long Yang ${ }^{1,3^{*}}$
}

${ }^{1}$ Department of Physiology, College of Medicine, Nanchang University, Nanchang, China.

${ }^{2}$ Department of Nurse, Nanchang University Hospital, Nanchang 330006, Jiangxi, China.

${ }^{3}$ Department of Experimental Teaching Center, Nanchang University, Nanchang, China.

[Received March 10, 2020; Revised April 25, 2020; Accepted April 27, 2020]

\begin{abstract}
Vascular dementia (VaD) is a neurodegenerative disease, with cognitive dysfunction attributable to cerebrovascular factors. At present, it is the second most frequently occurring type of dementia in older adults (after Alzheimer's disease). The underlying etiology of $\mathrm{VaD}$ has not been completely elucidated, which limits its management. Currently, there are no approved standard treatments for VaD. The drugs used in VaD are only suitable for symptomatic treatment and cannot prevent or reduce the occurrence and progression of VaD. This review summarizes the current status of pharmacological treatment for $\mathrm{VaD}$, from the perspective of the molecular mechanisms specified in various pathogenic hypotheses, including oxidative stress, the central cholinergic system, neuroinflammation, neuronal apoptosis, and synaptic plasticity. As VaD is a chronic cerebrovascular disease with multifactorial etiology, combined therapy, targeting multiple pathophysiological factors, may be the future trend in VaD.
\end{abstract}

Key words: Vascular dementia, pharmacological treatment; oxidative stress, central cholinergic system, neuroinflammation, neuronal apoptosis, synaptic plasticity

Vascular dementia $(\mathrm{VaD})$, characterized by progressive cognitive dysfunction, is generally considered the second most common type of dementia in older adults, after Alzheimer's disease (AD). $\mathrm{VaD}$ accounts for approximately $15 \%$ to $20 \%$ of dementia cases in North America and Europe [1], and has somewhat higher estimates, around 30\%, in Asia and developing countries [2]. In China, the incidence of $\mathrm{VaD}$ is 2.42 per 1000 person-years in individuals aged 60 years or above $[3,4]$. Although patients with $\mathrm{VaD}$ constitute the second largest dementia population in the world, treatment data are lacking. $\mathrm{VaD}$ causes a continuous and irreversible deterioration in the quality of life, resulting in huge medical and economic burdens on families and society.
$\mathrm{VaD}$ has multifactorial etiopathology, diverse clinical manifestations, and multiple clinical subtypes. Moreover, the diagnostic criteria are not consistent worldwide. Current international diagnostic criteria mainly include the DSM-5 [5], ICD-11 [6], VASCOG [7], ADDTC [8], and NINDS-AIREN [9]. Although these clinical diagnostic criteria have varying features, they all contain the following three elements: (1) diagnostic criteria for dementia are met; (2) there is evidence of cerebrovascular disease; and (3) there is a mutually causal relationship between dementia and cerebrovascular disease [10]. Unfortunately, ideal indicators for clinical diagnosing are lacking. Pathological examination is the only gold standard for diagnosis, but its implementation is difficult.

*Correspondence should be addressed to: Dr. Shu-Long Yang (Email: slyang@ncu.edu.cn) and Dr. Fen-Fang Hong (Email: hongfenfang@126.com), Department of Experimental Teaching Center, Nanchang University, Nanchang 330031, China.

Copyright: () 2020 Kuang H et al. This is an open-access article distributed under the terms of the Creative Commons Attribution License, which permits unrestricted use, distribution, and reproduction in any medium, provided the original author and source are credited. 
The Hachinski Ischemic Scale (HIS) can also be used for the identification of $\mathrm{VaD}$ and $\mathrm{AD}$ [11]. Because of its convenient implementation and high reliability, the HIS is widely used in the clinic. In recent years, the concept of vascular cognitive impairment (VCI) was delineated, with classifications of VCI-no dementia, $\mathrm{VaD}$, and mixed dementia ( $\mathrm{AD}$ and $\mathrm{VaD}$ ) [12]. The introduction of $\mathrm{VCI}$ has mitigated shortcomings in the clinical diagnosing of $\mathrm{VaD}$, greatly advancing the diagnostic time and providing a basis for early intervention.

However, the pathogenesis of $\mathrm{VaD}$ still remains unclear. Although the symptoms of $\mathrm{VaD}$ are similar to those in $\mathrm{AD}$, patients with $\mathrm{VaD}$ show a chronic decrease in cerebral blood flow, which differs from the brain changes in AD [13]. Several types of vascular lesions can trigger the molecular mechanisms leading to $\mathrm{VaD}$, including chronic cerebral hypoperfusion $(\mathrm{CCH})$, small vessel disease (leukoaraiosis and lacunar infarcts), microinfarcts, microhemorrhages, cerebral amyloid angiopathy, and mixed vascular lesions [14, 15]. CCH has been reported as the main cause of $\mathrm{VaD}[14,16]$. $\mathrm{CCH}$ can lead to a series of pathophysiological changes that contribute to cognitive deficits, eventually causing $\mathrm{VaD}$. $\mathrm{CCH}$-induced $\mathrm{VaD}$ animal models have implicated oxidative stress, central cholinergic system dysfunction, neuroinflammation, neuronal apoptosis, and synaptic plasticity dysfunction in the pathogenesis of $\mathrm{VaD}$. Thus, most of the drug targets in $\mathrm{VaD}$ are based on these five pathophysiological changes.

Currently, there are no approved standard treatments for $\mathrm{VaD}$. Furthermore, the drugs used in $\mathrm{VaD}$ are only suitable for symptomatic treatment and cannot prevent or delay the course of $\mathrm{VaD}$ [17]. Therefore, novel treatments in $\mathrm{VaD}$ are urgently needed. Based on the known pathophysiological changes in $\mathrm{VaD}$, a variety of pharmacological treatment approaches have been proposed. The objective of this report is to review the current progress in research regarding relevant therapeutic strategies and mechanisms in $\mathrm{VaD}$.

\section{Inhibition of oxidative stress}

Brain oxidative stress resulting from $\mathrm{CCH}$ is recognized as a major factor among the potential mechanisms of $\mathrm{VaD}$. Moreover, increased oxidative stress injury is considered to be a critical mechanism underlying cognitive deficits in $\mathrm{VaD}$ [14]. When brain ischemia and ischemia-reperfusion injuries occur, a large amount of lipid peroxidation products and free radicals are generated during oxidative stress. At this point, changes in cell membrane phospholipids lead to increased permeability, which promotes excessive edema and the release of excitatory transmitters. Finally, a series of chain reactions cause the demise of neurons [18]. The amount of neuronal necrosis continues to grow, and the size of the infarction increases, eventually leading to $\mathrm{VaD}$. Hence, drugs that inhibit oxidative stress show promise as a treatment for $\mathrm{VaD}$.

\subsection{Reduction of lipid peroxidation products}

Malondialdehyde (MDA) and 4-hydroxynonenal (4HNE) are common accessory substances of lipid peroxidation generated under oxidative stress conditions and are recognized as evaluation indexes for the degree of oxidative damage. An intermediate product of lipid peroxidation, reactive oxygen species (ROS), and the final decomposition products, MDA and 4-HNE, cause severe damage to the membrane structure and function, ultimately resulting in cytotoxicity [19]. Thus, reducing the production of intracellular lipid peroxidation products can have an antioxidant effect.

Tetramethylpyrazine nitrone (TBN) has shown neuroprotective properties in $\mathrm{VaD}$ rats through its antioxidant ability [20]. Studies have shown that TBN significantly suppresses the 4-HNE production in white matter and rescues cognitive deficits in $\mathrm{VaD}$ rats [20]. Alpha-lipoic acid (ALA) is a naturally occurring disulfide. It is considered to be a suitable neuroprotective agent, as it can cross the blood-brain barrier and be absorbed evenly in all parts of the central nervous system (CNS) [21]. Studies have revealed that ALA administration markedly reduces MDA and ROS production in the hippocampus of $\mathrm{CCH}$-induced $\mathrm{VaD}$ rats and improves learning and memory abilities. Therefore, it has been suggested that ALA improves cognitive deficits partly via its antioxidant effects [22]. Additionally, betain [23] and betulinic acid (BA) [24], two natural drugs, exert neuroprotective effects, similar to those of ALA, by suppressing oxidative stress in $\mathrm{VaD}$ rats. Furthermore, estrogen deficiency leads to increased free radical and lipid peroxidation production and decreased antioxidant enzymatic activity, resulting in reduced free radicalscavenging activity $[25,26]$. Biochanin A (BCA, a phytoestrogen) is an estrogen receptor ligand similar to estrogen. BCA effectively reduces oxidative damage by diminishing lipid peroxidation production, thus markedly improving learning and memory functions in $\mathrm{VaD}$ rats [27].

\subsection{Promotion of free radical scavenging}

As free radicals are thought to cause cognitive dysfunction, it is sensible to seek compounds that have antioxidant and neuroprotective properties against $\mathrm{VaD}$. The activities of antioxidant enzymes, such as superoxide dismutase (SOD), catalase (CAT), and glutathione 
(GSH), are decreased in patients with $\mathrm{VaD}[28,29]$. Furthermore, hypertension has been identified as a risk factor for $\mathrm{VaD}$ [30]. Studies have shown that hypertension is closely linked to the long-term risk of dementia and cognitive dysfunction $[31,32]$.

Antihypertensive treatment can reduce the risk of cognitive impairment by preventing the incidence of cerebrovascular diseases, such as $\mathrm{VaD}$. In animal models with hypertension-induced $\mathrm{VaD}$, the administration of TWK10-fermented soymilk extract improves cognitive function by inhibiting oxidative stress [33]. The administration of TWK10-fermented soymilk extract also increases the scavenging activity of $\alpha, \alpha$-diphenyl- $\beta$ picrylhydrazyl (DPPH) and the activity levels of CAT, GSH, and SOD [33]. Additionally, 1-phenylisatin, a selective cannabinoid receptor type 2 (CB2R) agonist, has the same effects as those of TWK10-fermented soymilk extract in $\mathrm{CCH}$-induced $\mathrm{VaD}$ rats [34]. Edaravone is a novel free radical scavenger that ameliorates neuronal damage and exerts neuroprotective effects in neurodegenerative diseases $[35,36]$. Edaravone markedly inhibits oxidative stress by elevating SOD activity and reducing MDA and ROS levels in the hippocampus of $\mathrm{VaD}$ rats. Additionally, the administration of edaravone rescues the cognitive deficits in $\mathrm{VaD}$ rats [37]. Furthermore, simvastatin exerts antioxidant properties by scavenging ROS, instead of by lowing blood lipids [38]. Simvastatin also increases GSH activity and reduces MDA levels in the brain of animals with L-methionineinduced $\mathrm{VaD}$, ameliorating L-methionine-induced cognitive decline to some extent [39]. In addition, melatonin has neuroprotective properties against $\mathrm{CCH}$ injury, attributable to its antioxidant ability [40]. Melatonin increases SOD, CAT, and GSH levels, as well as the total antioxidant capacity (TAC), by upregulating senescence marker protein-30 (SMP30) and osteopontin $(\mathrm{OPN})$ in the hippocampus of $\mathrm{VaD}$ rats [41]. Thus, freeradical scavengers, such as melatonin, may be a treatment option to suppress oxidative stress and improve cognitive function in patients with $\mathrm{VaD}$.

Natural drugs with active ingredients also hold great promise in the treatment of $\mathrm{VaD}$. Administrations of the Sailuotong (SLT) formula [42], Jiji decoction [43], alphanaphthoflavone (ANF) [44], and in-vitro cultured calculus bovis (ICCB) [45], inhibit oxidative stress by increasing SOD and GSH activity in the hippocampus of $\mathrm{VaD}$ rats, markedly rescueing the cognitive deficits. SLT, a threeherb formula composed of Panax ginseng, Ginkgo biloba, and Crocus sativus, has been used to treat $\mathrm{VaD}$ [46]. Moreover, two random clinical trials (RCTs) have explored the efficacy and safety of SLT in $\mathrm{VaD}[47,48]$. In one clinical trial, 227 patients were randomly divided into experimental groups (SLT $360 \mathrm{mg}$ [114 patients] or $240 \mathrm{mg}$ [113 patients] for 52 weeks) or control groups
(SLT $360 \mathrm{mg}$ or $240 \mathrm{mg}$ [113 patients each] only from weeks 27 to 52). After treatment, the experimental groups had improved scores compared to those of the control groups [48]. Jiji decoction consists of six medicinal plants: Coptis chinensis, Alpinia oxyphylla Miq., Wolfberry, Cuscuta, Radix Rehmanniae, and Scutellaria baicalensis. In addition to improving the cognitive dysfunction in $\mathrm{VaD}$ rats, Jiji decoction significantly improves learning and memory functioning in normal animals [43]. The above results show the great advantages of natural drugs in $\mathrm{VaD}$ treatment, which may indicate a future research direction in $\mathrm{VaD}$ therapy. However, more relevant RCTs are needed to explore the safety and efficacy of these drugs.

\subsection{Regulation of relevant oxidative stress pathways}

The nuclear factor erythroid 2-related factor 2 (Nrf2)/heme oxygenase-1 (HO-1) signaling pathway is an important antioxidant stress signaling pathway. When activated, it regulates the release of antioxidant substances, thereby inhibiting oxidative stress [49]. Nrf2 is a primary transcription factor involved in regulating the body's natural antioxidative stress defense system. When stimulated by oxidative stress, it initiates the expression of the downstream gene, $\mathrm{HO}-1$, and plays a protective role in antioxidative stress [50]. Under physiological conditions, Nrf2 binds to Kelch-like ECH-associated protein 1 (Keap1). Under oxidative stress, Nrf2 is released from the Keap1-Nrf2 complex and transferred from the cytoplasm to the nucleus, where it binds to antioxidant response elements located in HO-1 promoter regions [51, $52]$.

Edaravone [53], resveratrol [54], chotosan [55], and dextromethorphan [56] can inhibit oxidative stress, improve the antioxidant capability in $\mathrm{VaD}$ model animals, exert neuroprotective effects, and alleviate cognitive impairment via the Nrf2/HO-1 pathway (Fig. 1). More specifically, edaravone increases SOD activity, while decreasing MDA levels in the hippocampus via Nrf2 signaling pathway activation, which is associated with extracellular regulated protein kinases (ERK1/2) [53]. It is well established that ERK phosphorylation is the core pathway implicated in the activation of Nrf2 [57]. Chotosan not only promotes HO-1 expression through the Nrf2 pathway, but also enhances the expression of NADPH/quinone oxidoreductase 1 (NQO1), and exerts better neuroprotective effects compared to those of edaravone [55]. Additionally, the co-administration of aripiprazole and cilostazol collectively suppressed oxidative stress-induced neurotoxicity through the ERK/Nrf2/HO-1 pathway in $\mathrm{H}_{2} \mathrm{O}_{2}$-induced HT22 cells [58]. This provides a theoretical basis for the use of combination pharmacological treatment in $\mathrm{VaD}$. 
NADPH oxidase (Nox), an enzyme complex that transfers electrons from the membrane and produces ROS, is involved in pathological conditions in neuronal cells [59]. It is well known that flavanones have free radical-scavenging activity [60]. (2R,3S)-pinobanksin-3cinnamate (PNC) is a new type of flavonoid extracted from Alpinia galanga Willd., with a neuroprotective effect on $\mathrm{H}_{2} \mathrm{O}_{2}$-damaged cells. Recent studies have demonstrated that PNC markedly reduces ROS levels, while elevating SOD and GSH activity, in $\mathrm{VaD}$ rats, thereby improving behavioral performance [61]. Specifically, these data suggest that PNC elevates Nrf2 levels, while reducing Nox1 levels, as the potential mechanism underlying its effects [61]. Therefore, balanced regulation between the Nox-dependent oxidation pathway and the Nrf2-dependent antioxidant pathway might provide benefits in the management of $\mathrm{VaD}$.

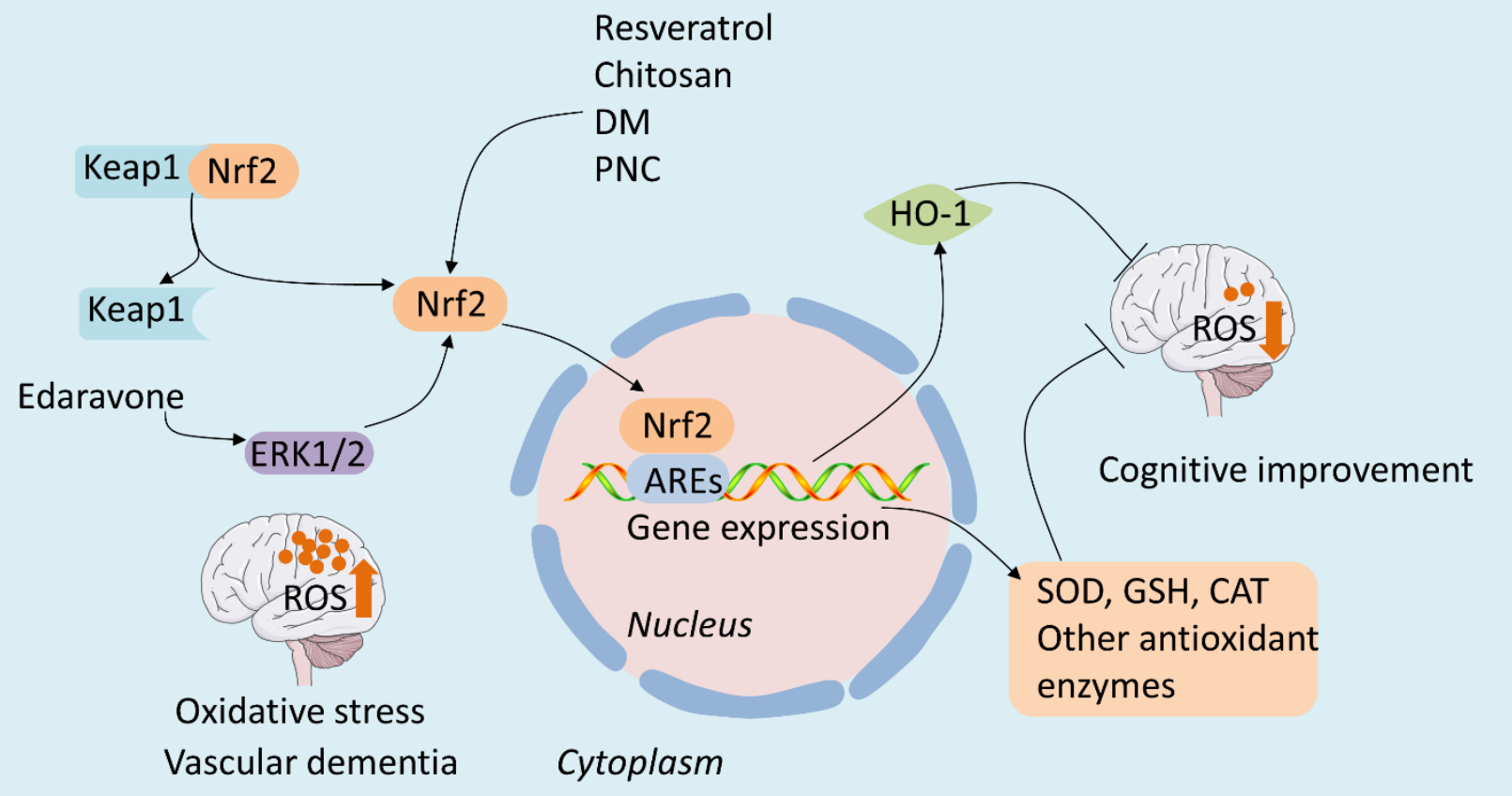

Figure 1. Drugs treat VaD through regulating the Nrf2/HO-1 signaling pathway. The Nrf2/HO-1 pathway plays an essential role in inhibiting the oxidative stress in the targets of treatment of $\mathrm{VaD}$. In the case of oxidative stress, Nrf2 is released from the Keap1Nrf2 complex, transferred from the cytoplasm to the nucleus, and binds to the AREs, promoting the expression of HO-1 and other antioxidant enzymes such as SOD, GSH, and CAT. These antioxidant substances could promote free radical scavenging and exert antioxidant and neuroprotective effects on $\mathrm{VaD}$. Resveratrol, chitosan, DM and PNC could up-regulate the expression of Nrf2, initiating the Nrf2/HO-1 pathway, thus inhibiting the oxidative damage and alleviating the cognitive deficits of VaD. ERK phosphorylation is the core pathway implicated in the activation of Nrf2. Edaravone could enhance the expression of ERK1/2 and then activate the Nrf2/HO-1 pathway, exerting neuroprotective effects on $\mathrm{VaD}$.

\section{Restoration of the central cholinergic system}

The central cholinergic system dysfunction has been found in $\mathrm{AD}$ cases, and acetylcholinesterase (AChE) inhibitors are presently the most commonly used agents in the treatment of AD [62,63]. Similarly, cholinergic dysfunction has also been documented in $\mathrm{VaD}$ cases [64]. Therefore, patients with $\mathrm{VaD}$ may also benefit from central cholinergic system restoration. Current evidence suggests that cholinergic drugs may be utilized for symptomatic treatment of patients with $\mathrm{VaD}$ with cognitive impairment [65].

\subsection{Inhibition of AchE activity}

The presence of significantly elevated AChE activity indicates cholinergic damage in the hippocampus, which triggers cognitive deficits, in patients with $\mathrm{VaD}$ [64]. As in $\mathrm{AD}, \mathrm{AChE}$ inhibitors may exert benefits in patients with $\mathrm{VaD}$. This is the theoretical basis for the early use of AChE inhibitors to alleviate $\mathrm{VaD}$ symptoms.

Although there are currently no officially approved drugs for $\mathrm{VaD}$ treatment, $\mathrm{AChE}$ inhibitors in $\mathrm{VaD}$ are widely used in clinical practice. Evidence from numerous studies, including RCTs, supports the advantages of AChE inhibitor drugs, such as donepezil [66-70], 
galantamine [71-74], and rivastigmine [75-78]. The administration of these agents results in significant improvements in cognition, global function, and ability. However, AChE inhibitors do not always provide consistent cognitive results among potential cases of $\mathrm{VaD}$ in elderly patients. This suggests that the putative cholinergic deficiency in $\mathrm{VaD}$ may reflect the presence of concomitant $\mathrm{AD}$ pathology. Therefore, it is necessary to establish specific clinical diagnostic criteria for $\mathrm{VaD}$ and perform multi-center, large sample, long-term RCTs to better evaluate the efficacy of $\mathrm{AChE}$ inhibitor drugs in $\mathrm{VaD}$.

In addition to the three $\mathrm{AChE}$ inhibitors mentioned above, other AChE inhibitors may have protective effects against $\mathrm{VaD}$. Administration of the estrogen analogue, $\mathrm{BCA}$, markedly reduces $\mathrm{AChE}$ activity in $\mathrm{VaD}$ rats [27]. Ryanodine and cysteinyl leukotriene 1 receptors (RyRs and CysLT1Rs, respectively) are widely present in the CNS and are implicated in cognition and inflammation regulation [79]. Administration of ruthenium red (a RyRs antagonist) and montelukast (a CysLT1Rs antagonist) considerably attenuates $\mathrm{CCH}$-induced cholinergic dysfunction by suppressing AChE activity, reducing the cognitive impairment and brain damage [80]. Thus, the modulation of RyRs and CysLT1Rs may provide a therapeutic target in $\mathrm{CCH}$-induced disorders, such as $\mathrm{VaD}$.

Hwangryunhaedok-tang (HRT) is a four-herb formulation consisting of the following medicinal plants in a 1:1:1:1 ratio: Phellodendri Cortex, Scutellariae Radix, Coptidis Rhizoma, and Gardeniae Fructus [81]. HRT inhibits AChE activity, restores acetylcholine (Ach) levels, and alleviates memory impairments and neuronal damage in $\mathrm{CCH}$-induced $\mathrm{VaD}$ rats [64]. These results demonstrate the therapeutic effects of HRT as a cholinergic drug for $\mathrm{VaD}$. Additionally, simvastatin [39], ST09 (a novel thioester derivative of 6-chloro-tacrine) [82], and the co-administration of melatonin and resveratrol [83] significantly decrease AChE activity and rescue cognitive deficits in $\mathrm{VaD}$ rats. Although these results are encouraging, RCTs are still needed to evaluate the safety and efficacy of these agents in the treatment of $\mathrm{VaD}$.

\subsection{Promotion of ChAT expression}

Ach is an important neurotransmitter involved in learning and memory functions of the CNS. Accordingly, decreased Ach synthesis inevitably leads to cognitive dysfunction and, eventually, VaD. Studies have reported that choline acetyltransferase (ChAT) activity, a synthetic bioenzyme for Ach, is reduced in the hippocampus of $\mathrm{VaD}$ rats $[84,85]$. BCA [27] has estrogen-like effects and can enhance ChAT expression in rat hippocampal cholinergic neurons; thus, $\mathrm{BCA}$ exhibits a certain degree of protection against memory impairment in $\mathrm{VaD}$ rats. Additionally, some scholars have proposed that estrogen can improve $\mathrm{VaD}$ symptoms in model animals by increasing the calcium load and calbindin-d28k [86] and VEGF [87] expression, suggesting that estrogen plays an anti- $\mathrm{VaD}$ role via multiple molecular mechanisms. Erythropoietin (EPO) also has potential therapeutic use, in terms of neuroprotection, as studies have demonstrated that EPO can improve white integrity after cerebral ischemia [88, 89]. EPO administration rescues cholinergic dysfunction through the restoration of ChAT activity and Ach levels, and the inhibition of AchE activity, in $\mathrm{VaD}$ rats [90]. These data support the behavioral effects, and suggest that EPO may exert its neuroprotection by rescuing cholinergic function. In addition, ALA administration rescues cholinergic dysfunction by increasing ChAT activity and Ach levels [22]. Thus, the neuroprotective properties of ALA in the central cholinergic system represent another mechanism for treating $\mathrm{VaD}$.

Additionally, natural drugs, such as the ethanolic extract of Fructus mume ( $F$. mume) from the unripe fruit of Prunus mume, have been reported to reverse cognitive deficits caused by $\mathrm{CCH}$ via central cholinergic system restoration [91, 92]. Moreover, F. mume administration restores ChAT expression in the hippocampus, suggesting that $F$. mume is a promising agent for the treatment of $\mathrm{VaD}[93]$.

\section{Inhibition of neuroinflammation}

Neuroinflammation is an important process in the etiology of $\mathrm{VaD}$. The memory recovery effect is associated with cerebral ischemia-induced expression of inflammatory factors [94]. The expression levels of various inflammatory cytokines in brain tissue are abnormally increased in $\mathrm{VaD}$ [95]. Additionally, increased inflammatory responses, such as the activation of main inflammatory cells in brain tissue [95] and inflammation-related signaling, have been reported in animal models of $\mathrm{VaD}$ [64]. Accordingly, drugs that only target neuronal protection cannot achieve the expected results. Therefore, proper consideration should be given to the role of neuroinflammatory responses in $\mathrm{VaD}$, as this is conducive to the development of new drugs.

\subsection{Suppression of inflammatory cytokines}

The inflammatory response leads to an up-regulation of pro-inflammatory cytokines, such tumor necrosis factor- $\alpha$ (TNF- $\alpha$ ), interleukin-6 (IL-6), and interleukin-1 $\beta$ (IL-1 $\beta$ ), 
and can aggravate the degree of neuroinflammation after $\mathrm{CCH}$ [24].

The CB2R agonist, WIN55,212-2 (WIN), has neuroprotective effects in focal cerebral ischemia [96] and $\mathrm{AD}$ [97]. Recent studies have shown that IL- $1 \beta$ and TNF$\alpha$ are markedly elevated in $\mathrm{VaD}$ rats, accompanied by increased autophagy. However, after the administration of WIN, the levels of inflammatory cytokines (IL-1 $\beta$ and TNF- $\alpha$ ), and expression of autophagy-related factors [microtubule-associated protein 1 light chain 3 (LC-3) and beclin-1], were significantly suppressed. Additionally, behavioral experiments indicate that WIN rescues the cognitive deficits in $\mathrm{VaD}$ rats [98]. These results indicate that WIN exerts neuroprotective properties, supporting cognition function in $\mathrm{VaD}$ rats, potentially related to the inhibition of inflammation and abnormal autophagy. Similarly, another selective CB2R agonist, paeoniflorin (PF), can significantly attenuate $\mathrm{CCH}$-induced impairments in learning and memory in $\mathrm{VaD}$ rats. In addition to inhibiting pro-inflammatory cytokines, such as IL-1 $\beta$, IL-6, TNF- $\alpha$, and NO, PF also significantly up-regulates the expression of antiinflammatory cytokines, IL-10 and transforming growth factor beta 1 (TGF- $\beta 1$ ) [99, 100]. Based on the above research, three selective CB2R agonists, 1-phenylisatin, WIN, and PF, can improve cognitive impairments in $\mathrm{VaD}$ via various molecular mechanisms, suggesting that they constitute a very promising target for pharmacological treatment in $\mathrm{VaD}$.

Additionally, the administration of bee venom (BV) has been shown to alleviate cognitive impairment and decrease the expression levels of neuroinflammatory cytokines, including ionized calcium binding adaptor molecule 1 (Iba-1), CD14, and TNF- $\alpha$, in the hippocampus of $\mathrm{VaD}$ rats [101]. Moreover, the underlying mechanism of the pharmacological effect of BV may be mediated via the neuroinflammation-related toll-like receptor 4 (TLR4) signaling pathway [101].

\subsection{Suppression of glial activation}

Chronic cerebral ischemia causes the proliferation and activation of glia, such as microglia and astrocytes, thereby producing a large number of inflammatory cytokines and oxygen free radicals, which are implicated in the pathogenesis of $\mathrm{VaD}[102,103]$. CD11b [104] and glial fibrillary acidic protein (GFAP) [105] are characteristic markers of microglia and astrocytes, respectively, and their expression reflects the proliferation and activation of both types of cells.

The administration of Yangxue Qingnao granules (YQG) can rescue the elevated expression of $\mathrm{CD} 11 \mathrm{~b}$ and GFAP in the CA1 region of the hippocampus in VaD rats [106]. YQG includes Radix angelicae sinensis, Radix paeoniae alba, Rhizoma chuanxiong, Caulis spatholobi, Radix rehmanniae preparata, Ramulus uncariae cum uncis, Spica prunellae, Semen cassiae, Concha margaritifera usta, Rhizoma corydalis yanhusuo, and Herba asari [107]. This result indicates that YQG may play a therapeutic role in $\mathrm{VaD}$ by inhibiting glial proliferation and activation. Additionally, carnosine administration suppresses glial activation by attenuating the elevated expression levels of GFAP and Iba-1, thereby ameliorating the white matter lesion and cognitive impairments [105]. Iba- 1 is another marker of microglia activation and has significantly increased expression in $\mathrm{VaD}$ rats [101]. Scutellarin (SCT), a major flavonoid in the medicinal herb of Erigeron breviscapus (vant.) Hand. Mazz., also exhibits neuroprotective effects. SCT significantly inhibits the activation of Iba1-expressing microglia in brain tissues, and ameliorates cognitive impairments caused by $\mathrm{CCH}$ [108]. Palmitoylethanolamide (PEA) is a prototype ALIAmide, well-known for its analgesic, antiinflammatory, and neuroprotective properties. Recent studies have demonstrated that PEA oxazoline (PEAOXA) administration significantly alleviates the pathological changes and neuronal death caused by $\mathrm{CCH}$ and rescues behavioral dysfunction [109]. Furthermore, PEA-OXA reduces GFAP and Iba-1 expression, thereby inhibiting the activation of microglia and astrocytes [109]. Thus, PEA-OXA may become a new target for suppressing the neuroinflammatory response in $\mathrm{VaD}$. Additionally, recent studies have reported that SLT administration suppresses neuroinflammation by inhibiting astrocytic reactions in $\mathrm{VaD}$ rats [94].

\subsection{Regulation of inflammation-related signaling pathways}

The role of inflammasomes in neurodegenerative diseases has been recently described [110, 111]. Furthermore, elevated hippocampal NLR family pyrin domain containing 3 (NLRP3) expression indicates that the upregulation of NLRP3 is related to $\mathrm{CCH}$-induced neuroinflammation $[112,113]$. Notably, NLRP3 inflammasome activation initiates the proteolytic activity of caspase-1, which is necessary for the secretion of the inflammatory cytokine, IL-1 $\beta$ [114]. Additionally, nuclear factor kappa B (NF- $\mathrm{kB}$ ) signaling is a well-known neuroinflammatory regulatory pathway. NF- $\kappa \mathrm{B}$ is an important transcription factor in the inflammatory response. Cerebral ischemia and hypoxia can cause a large amount of NF- $\mathrm{\kappa B}$ activation, promoting inflammatory infiltration and increasing the expression levels of inflammatory cytokines, such as TNF- $\alpha$ and IL- $1 \beta[115$, 116]. Furthermore, the mitogen-activated protein kinase (MAPK) signaling pathway is involved in the process of 
microglial activation. Lipocalin-2 (LCN2) is another inflammatory factor that is a target in regulating astrocytic reactions, and plays a detrimental role in the ischemic brain and neurodegenerative diseases $[117,118]$.

3-[2-[4-(3-chloro-2-methylphenyl)-1-piperazinyl] ethyl]-5,6-dimethoxyindazole (DY-9836), a calmodulin inhibitor [119], can mitigate hippocampal-dependent cognitive deficits in $\mathrm{VaD}$ rats. Moreover, these neuroprotective properties are linked to a significant reduction in peroxynitrite formation, which is associated with down-regulation of NLRP3/caspase-1/IL-1 $\beta$ signaling [112]. Additionally, sirtuin 1 (SIRT1) modifies the Lys310 residue of RelA/P65 by deacetylation, and inhibits NF- $\kappa \mathrm{B}$ transcriptional activity, thereby reducing its inflammatory response and the expression of inflammatory cytokines [120]. Triptolide administration improves cognitive impairments in $\mathrm{VaD}$ rats, increases SIRT1 expression, and decreases NF- $\kappa$ B expression; thus, its mechanism may be related to SIRT1/NF- $\kappa$ B signaling [121]. In addition, mammalian target of rapamycin complex 1 (mTORC1) is an essential factor in regulating glial functions. Studies have suggested that everolimus (RAD001), a rapamycin analogue, suppresses mTORC1 expression, and ameliorates cognitive deficits through microglia M1/M2 balance restoration in $\mathrm{VaD}$ rats [122]. Thus, RAD001 is considered as a potential pharmacological treatment for $\mathrm{VaD}$.

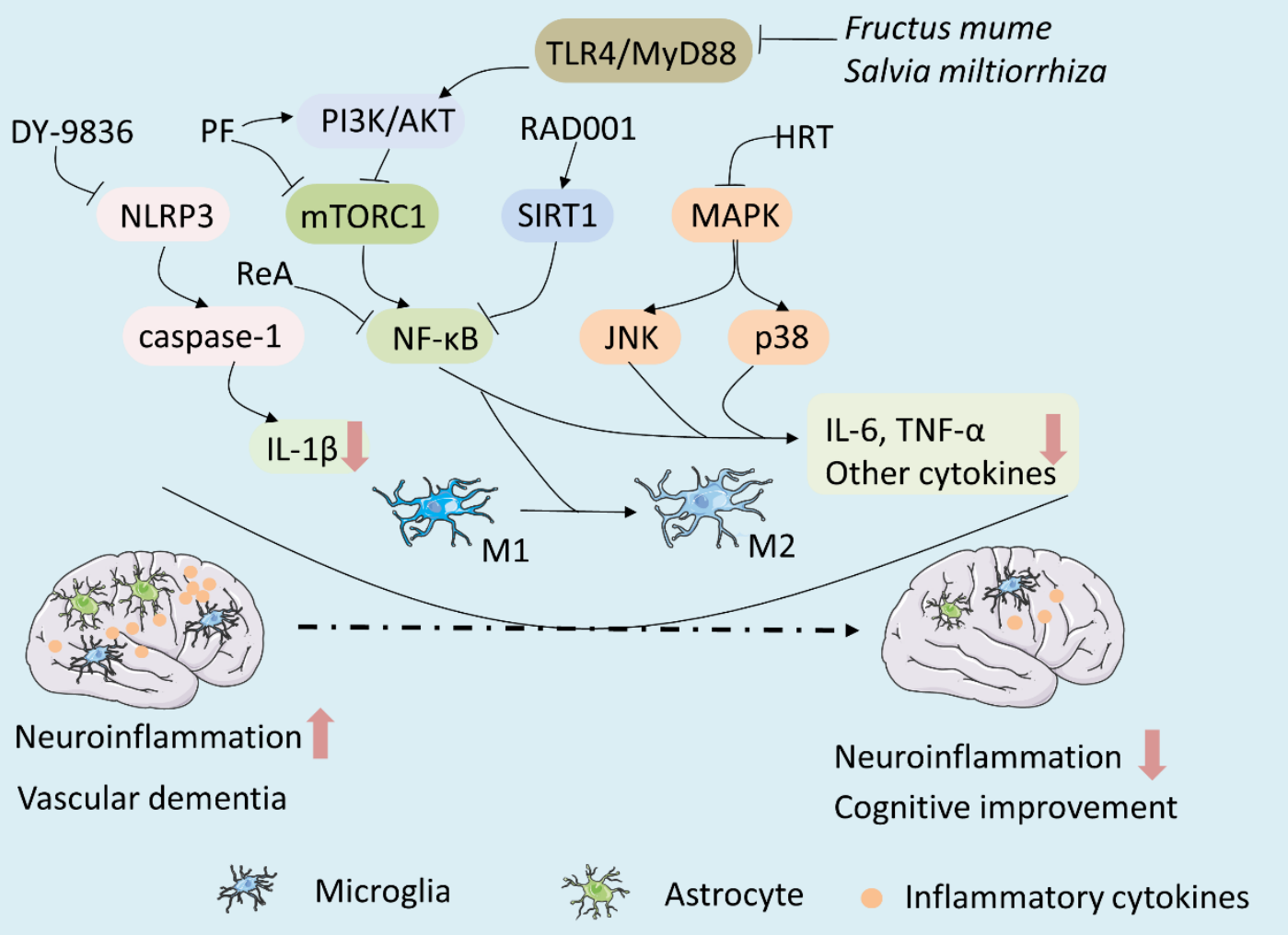

Figure 2. Drugs treat VaD through regulating inflammation-related signaling pathways. There are several inflammationrelated pathways involved in neuroinflammation of $\mathrm{VaD}$, which can be used as pharmacological targets. The NF- $\mathrm{B}$ signaling is a core pathway among these inflammation-related pathways. Some drugs such as ReA, PF, Fructus mume, Salvia miltiorrhiza, and RAD001 can act directly on NF- $\mathrm{BB}$ or its upstream molecules, thereby inhibiting the pro-inflammatory pathways, reducing expression of inflammatory cytokines, suppressing the activation of glia and promoting the polarization of M1/M2. These effects are beneficial to the cognitive improvement of VaD. Other inflammation-related signaling pathways, such as NLRP3/caspase-1/IL-1 $\beta$ and MAPK signaling could be inhibited by DY-9836 and HRT respectively. Hence, these drugs can exert a neuroprotective effect on $\mathrm{VaD}$.

In addition to alleviating cognitive dysfunction through cholinergic dysfunction rescue, the herbal formula, HRT, can inhibit neuroinflammation by regulating p-Jun N-terminal kinase (JNK) and p38 MAPK pathways in the hippocampus of $\mathrm{VaD}$ rats [64].
Additionally, other natural drugs, such as $F$. mume [123] and Salvia miltiorrhiza [124], can alleviate cognitive impairments through the inhibition of neuroinflammation by down-regulating TLR4/myeloid differentiation factor 88 (MyD88) and p38 MAPK signaling. Moreover, the 
CB2R agonist, PF [99], has been shown to exert an antineuroinflammatory effect in $\mathrm{VaD}$ rats, by significantly inhibiting $\mathrm{CCH}$-induced mammalian target of mTORC1/ NF- $\kappa B$ pro-inflammatory pathway signaling and enhancing phosphatidylinositol-3 kinase (PI3K)/ protein kinase $\mathrm{B}$ (AKT/PKB) anti-inflammatory pathway signaling [99] (Fig. 2). Furthermore, treatment with SLT decreases LCN2 expression and the phosphorylation levels of Janus kinase-2 (JAK2) and signal transducer and activator of transcription-3 (STAT3) and mitigates the cognitive deficits in $\mathrm{VaD}$ rats. These results suggest that SLT inhibits neuroinflammation in $\mathrm{VaD}$ rats via the LCN2-JAK2/STAT3 pathway, providing insight into a promising therapeutic strategy in $\mathrm{VaD}$ [94]. Finally, rehmannioside $\mathrm{A}(\mathrm{Re} \mathrm{A})$ is isolated from Rehmanniae Radix and exhibits a protective role against $\mathrm{VaD}$. Studies have found that the administration of ReA attenuates the cognitive deficits and histological alterations of the hippocampus in $\mathrm{VaD}$ rats, partly due to the inactivation of NF- $\mathrm{B}$ [125].

\section{Inhibition of neuronal apoptosis}

$\mathrm{VaD}$ is a multifactorial disorder. The mechanism of neuronal apoptosis is of great significance for understanding its pathogenesis. Emerging data demonstrate that cell survival regulation requires a series of proteins associated with apoptosis, including Bax, Bcell lymphoma-2 (Bcl-2), and caspase-3. However, their expression is abnormal in $\mathrm{VaD}$. Inhibiting neuronal apoptosis may be beneficial in treating $\mathrm{VaD}[42,122]$.

\subsection{Suppression of caspase-3 activation}

Caspase- 3 is the main terminal cleaving enzyme in the process of apoptosis. Caspase-3 expression is elevated considerably in $\mathrm{VaD}$ rats $[42,126]$. Administration of ReA [122], ligustilide [127], osthole [128], and SLT [42] has been reported to prevent caspase- 3 activation and reverse the loss of hippocampal neurons, as well as the cognitive deficits, induced by $\mathrm{CCH}$. In addition to inhibiting oxidative stress and AchE activity, the natural drug resveratrol (mentioned above), can also suppress neuronal apoptosis by reducing apoptotic proteins, such as caspase- 3 , in the hippocampus of $\mathrm{VaD}$ rats, thereby relieving the symptoms of $\mathrm{VaD}$ [129]. These results indicate that anti-apoptotic effects mediated by the suppression of caspase-3 activation might contribute to improvements in cognitive function in $\mathrm{VaD}$.

\subsection{Suppression of $\mathrm{Bax} / \mathrm{Bcl}-2$ ratio}

The Bax/Bcl-2 ratio also plays a role in cell apoptosis $[130,131]$. Bcl-2 and Bax are two major proteins that regulate apoptosis and have opposing functions. Bcl-2 is a functional inhibitor of apoptosis, while $\mathrm{Bax}$ is a promoter of apoptosis. A higher Bax/Bcl-2 ratio indicates stronger pro-apoptotic ability, and a lower ratio indicates less pro-apoptotic ability. Immunohistochemical results demonstrate that Bax expression is remarkably increased, and $\mathrm{Bcl}-2$ expression is decreased, in $\mathrm{VaD}$ rats, resulting in a high $\mathrm{Bax} / \mathrm{Bcl}-2$ ratio $[45,126]$. The administration of ICCB [45], osthole [128], PNC [61], Panax ginseng [132], total harmaline alkaloid extract [133], and SLT [42] reduces the Bax/Bcl-2 ratio and exerts anti-apoptotic properties in the brain of $\mathrm{VaD}$ rats, alleviating the cognitive deficits. Based on the above research, the Chinese medicinal formula, SLT, can improve $\mathrm{VaD}$ symptoms via multiple mechanisms, including oxidative stress, neuroinflammation, and neuronal apoptosis. These results indicate SLT as a promising drug for the treatment of $\mathrm{VaD}$.

\subsection{Regulation of apoptosis-related pathways}

The inflammatory cytokine, monocyte chemotactic protein 1 (MCP-1), and oxidative stress factor, homocysteine (Hcy), are involved in promoting apoptosis by up-regulating the $\mathrm{Bax} / \mathrm{Bcl}-2$ ratio, while brainderived neurotrophic factor (BDNF) acts as an antiapoptotic factor by down-regulating MCP-1 and Hcy [126]. MCP-1 and Hcy expression levels are markedly elevated, while the BDNF level is significantly reduced, in $\mathrm{VaD}$ models. The PI3K/AKT signaling pathway can also down-regulate the $\mathrm{Bax} / \mathrm{Bcl}-2$ ratio, alleviating neuronal apoptosis [134]. Additionally, the AKT/mTOR pathway is upstream to the signaling regulating neuronal apoptosis $[135,136]$.

L-3-n-butylphthalide (L-NBP) is a type of antiischemic cranial neuroprotective agent used in CNS diseases, such as ischemic brain injury [137-139]. L-BNP administration protects against $\mathrm{VaD}$ through a reduction in hippocampal neuronal apoptosis by suppressing the Bax/Bcl-2 ratio. The potential underlying molecular mechanism involves activation of the PI3K/AKT signaling pathway [140, 141]. However, glial line-derived neurotrophic factor (GDNF)/GDNF family receptor alpha-1 (GFR $\alpha 1) /$ receptor tyrosine kinase (Ret) and AKT/ERK1/2 signaling pathways are also implicated in the protective effect of L-BNP against hippocampal neuronal apoptosis in $\mathrm{VaD}$. GDNF/GFR $\alpha 1 /$ Ret signaling and neuronal viability can be maintained by L-NBP, which activates p-AKT and p-ERK1/2 and decreases the $\mathrm{Bax} / \mathrm{Bcl}-2$ ratio and the expression of cleaved caspase-3 [142]. However, recent studies have also found that LNBP can exert protective effects against cognitive deficits in $\mathrm{VaD}$ rats through the inhibition of autophagy (decreased LC-3 and Beclin-1) via mTORC1 pathway up- 
regulation [143]. This implies that L-NBP is a promising multiple-target drug for the treatment and prevention of $\mathrm{VaD}$. Additionally, the $\mathrm{CB} 2 \mathrm{R}$ agonist, WIN, protects against cognitive impairment in $\mathrm{CCH}-\mathrm{VaD}$ rats via PI3K/AKT signaling [144]. WIN administration can also ameliorate hippocampal neuronal damage after $\mathrm{CCH}$ by altering apoptosis signal-regulating kinase 1 (ASK1)-p38 signaling. After the administration of WIN, the expression of phosphorylated ASK1 and p38 is markedly reduced, leading to decreased caspase- 9 and caspase- 3 expression in the hippocampus of $\mathrm{VaD}$ rats [145].

Administration of ligustrazine (extracted from Ligusticum Chuanxiong Hort.) attenuates $\mathrm{VaD}$ via the regulation of BDNF, MCP-1, and Hcy, leading to a low $\mathrm{Bax} / \mathrm{Bcl}-2$ ratio and caspase-3 inactivation [126]. These data suggest ligustrazine as a promising neuroprotective drug in $\mathrm{VaD}$ therapy. In addition, $\mathrm{PF}$ administration suppresses the Bax/Bcl-2 ratio by increasing BDNF levels in the hippocampus of $\mathrm{VaD}$ rats [146]. Finally, oxiracetam (ORC) is a nootropic drug that improves cognitive and memory deficits [147]. Studies have found that the administration of ORC markedly mitigates learning and memory deficits and neuronal damage in $\mathrm{VaD}$ rats via the inhibition of neuronal apoptosis (decreased Bax/Bcl-2 ratio) and autophagy (decreased LC-3 and Beclin-1) by up-regulating the AKT/mTOR pathway, thereby improving dementia symptoms [148]. These data suggest that ORC may become an effective drug for the treatment of $\mathrm{VaD}$ (Fig. 3).

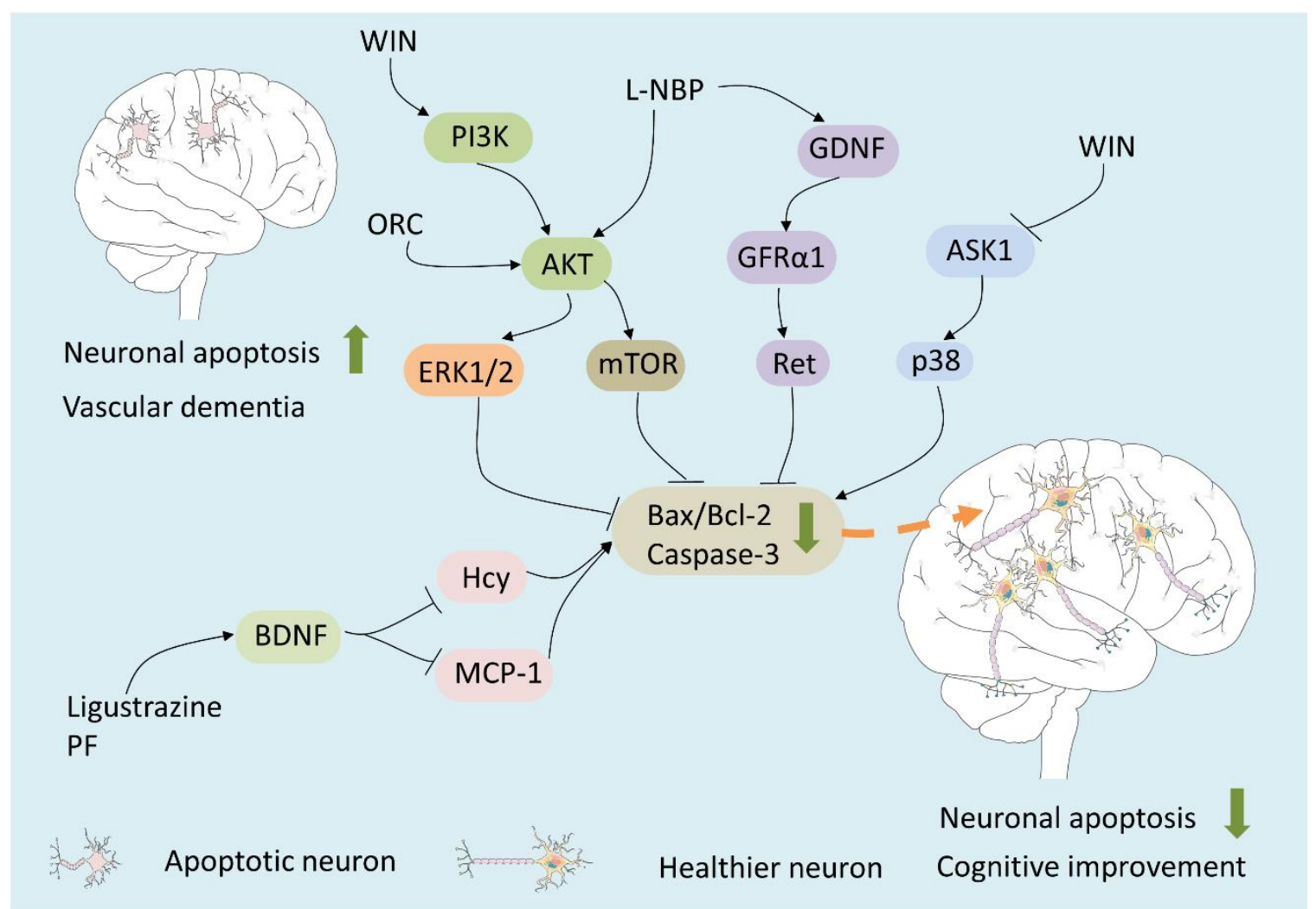

Figure 3. Drugs treat VaD through regulating apoptosis-related pathways. The mechanisms of neuronal apoptosis are of great significance for understanding the pathogenesis of $\mathrm{VaD}$. Similar to inflammation-related pathways, neuronal apoptosis also involved in several pathways. Administration of WIN can inhibit apoptosis through activating the PI3K/AKT pathway and blocking the ASK1/p38 pathway. Besides, the L-BNP can also inhibit apoptosis through GDNF/GFR $\alpha 1 /$ Ret and AKT/ERK1/2 pathways. The BDNF serves as an anti-apoptotic factor by down-regulating the pro-apoptotic factors MCP-1 and Hcy. Drugs, such as ligustrazine and PF, can suppress neuronal apoptosis by increasing BNDF levels. ORC also could inhibit neuronal apoptosis by up-regulating the AKT/mTOR pathway. The results of the aforementioned drugs will lead to a decrease in the Bax/Bcl-2 ratio and the expression of caspase-3. These effects are likely to improve cognitive deficits in $\mathrm{VaD}$.

\section{Restoration of synaptic plasticity}

Synaptic plasticity has long been considered as the neurobiological basis of cognition [149]. Synaptic plasticity also plays an essential role in $\mathrm{VaD}$. Synapse damage occurs in the early stages of $\mathrm{VaD}$, and the degree of damage is related to the degree of cognitive impairment. Studies have shown that, in 
animal models of $\mathrm{VaD}$, synaptic plasticity dysfunction is closely related to cognitive dysfunction [150, 151]. As major factors in the regulation of synaptic plasticity, N-methyl-Daspartic acid receptor (NMDAR; two subunits, NR2A and NR2B) and calmodulin-dependent protein kinase II (CaMKII) are closely associated with learning and memory functions $[152,153]$. In addition, long-term potentiation (LTP) can enhance synaptic transmission, which is closely related to hippocampal learning and memory formation [154]. Studies have found that LTP induction is damaged in the hippocampus of $\mathrm{VaD}$ rats and is correlated with reduced CaMKII protein levels [155]

Table 1. Drugs treat $\mathrm{VaD}$ through multiple targets mentioned in this article.

\begin{tabular}{|c|c|c|c|c|c|c|c|c|c|c|}
\hline \multirow[b]{2}{*}{$\begin{array}{l}\text { Drug } \\
\text { treatment }\end{array}$} & \multirow[b]{2}{*}{ Dose } & \multirow[b]{2}{*}{ Period } & \multicolumn{6}{|c|}{ Potential molecular mechanism } & \multirow[b]{2}{*}{$\begin{array}{l}\text { Effects } \\
\text { on VaD }\end{array}$} & \multirow[b]{2}{*}{ Ref. } \\
\hline & & & $\begin{array}{l}\text { Oxidative } \\
\text { stress }\end{array}$ & $\begin{array}{l}\text { Central } \\
\text { cholinergic } \\
\text { system }\end{array}$ & $\begin{array}{l}\text { Neuro- } \\
\text { inflammation }\end{array}$ & $\begin{array}{l}\text { Neuronal } \\
\text { apoptosis }\end{array}$ & $\begin{array}{l}\text { Synaptic } \\
\text { plasticity }\end{array}$ & $\begin{array}{l}\text { Experimental } \\
\text { VaD model }\end{array}$ & & \\
\hline TBN & $\begin{array}{l}30 \\
\mathrm{mg} / \mathrm{kg} \\
\text { i.v. }\end{array}$ & 7 days & $4-\mathrm{HNE} \downarrow$ & & $\begin{array}{l}\text { Glial } \\
\text { activation } \downarrow\end{array}$ & $\begin{array}{l}\mathrm{Bax} / \mathrm{Bcl}- \\
2 \downarrow \\
\text { caspase-3 } \\
\downarrow\end{array}$ & & $\begin{array}{l}\text { In vivo } 2 \mathrm{VO} \\
\text { rats }\end{array}$ & $\begin{array}{l}\mathrm{CBF} \uparrow, \\
\text { learning } \\
\text { and } \\
\text { memory } \\
\uparrow\end{array}$ & {$[20]$} \\
\hline ALA & $\begin{array}{l}50 \\
\mathrm{mg} / \mathrm{kg}, \\
\text { i.p. }\end{array}$ & $\begin{array}{l}28 \\
\text { days }\end{array}$ & $\begin{array}{l}\text { MDA and } \\
\text { ROS } \downarrow ; \\
\text { GSH } \uparrow\end{array}$ & $\begin{array}{l}\text { AchE } \downarrow \text {, } \\
\text { ChAT and } \\
\text { Ach } \uparrow\end{array}$ & & & & $\begin{array}{l}\text { In vivo } 2 \mathrm{VO} \\
\text { rats }\end{array}$ & $\begin{array}{l}\text { Learning } \\
\text { and } \\
\text { memory } \\
\uparrow\end{array}$ & {$[22]$} \\
\hline Betaine & $\begin{array}{l}12 \\
\mathrm{mg} / \mathrm{kg}, \\
\text { i.g. }\end{array}$ & $\begin{array}{l}14 \\
\text { days }\end{array}$ & $\begin{array}{l}\text { MDA and } \\
\text { ROS } \downarrow ; \\
\text { SOD and } \\
\text { GSH } \uparrow\end{array}$ & & & & $\begin{array}{l}\text { PSD93,95 } \\
\text { and } \\
\text { MAP2 } \uparrow\end{array}$ & $\begin{array}{l}\text { In vivo } 2 \mathrm{VO} \\
\text { rats }\end{array}$ & $\begin{array}{l}\text { Learning } \\
\text { and } \\
\text { memory } \\
\uparrow\end{array}$ & {$[23]$} \\
\hline BA & $\begin{array}{l}10 \text { and } \\
15 \\
\mathrm{mg} / \mathrm{kg} \text {, } \\
\text { i.g. }\end{array}$ & 7 days & $\begin{array}{l}\text { MDA } \downarrow ; \\
\text { GSH } \uparrow\end{array}$ & $\operatorname{AchE} \downarrow$ & $\begin{array}{l}\text { TNF- } \alpha \text { and } \\
\text { IL- } 1 \beta \downarrow\end{array}$ & & $\mathrm{BDNF} \uparrow$ & $\begin{array}{l}\text { In vivo } 2 \mathrm{VO} \\
\text { rats }\end{array}$ & $\begin{array}{l}\mathrm{CBF} \uparrow \text {, } \\
\text { learning } \\
\text { and } \\
\text { memory } \\
\uparrow\end{array}$ & {$[24]$} \\
\hline BCA & $\begin{array}{l}2.5 \text { and } \\
5 \\
\mathrm{mg} / \mathrm{kg} \text {, } \\
\text { i.g. }\end{array}$ & $\begin{array}{l}14 \\
\text { days }\end{array}$ & TBARS $\downarrow$ & $\operatorname{AchE} \downarrow$ & & & & $\begin{array}{l}\text { In vivo } \\
\text { dyslipidemic } \\
\text { rats }\end{array}$ & $\begin{array}{l}\text { Learning } \\
\text { and } \\
\text { memory } \\
\uparrow\end{array}$ & {$[27]$} \\
\hline TWK10 & $\begin{array}{l}\text { Flexible } \\
\text { dose }\end{array}$ & $\begin{array}{l}35 \\
\text { days }\end{array}$ & $\begin{array}{l}\text { MDA and } \\
\text { DPPH } \downarrow ; \\
\text { CAT, } \\
\text { SOD and } \\
\text { GSH } \uparrow\end{array}$ & $\operatorname{AchE} \downarrow$ & & & & $\begin{array}{l}\text { In vivo } \\
\text { hypertension } \\
\text { rats }\end{array}$ & $\begin{array}{l}\text { Learning } \\
\text { and } \\
\text { memory } \\
\uparrow\end{array}$ & {$[33]$} \\
\hline Edaravone & $\begin{array}{l}5 \\
\mathrm{mg} / \mathrm{kg}, \\
\text { i.p. }\end{array}$ & $\begin{array}{l}35 \\
\text { days }\end{array}$ & $\begin{array}{l}\text { MDA and } \\
\text { ROS } \downarrow ; \\
\text { SOD } \uparrow\end{array}$ & & & & $\begin{array}{l}\text { PSD93, } \\
95 \uparrow ; \\
\text { CREB } \\
\text { and } \\
\text { NR2B } \uparrow\end{array}$ & $\begin{array}{l}\text { In vivo } 2 \mathrm{VO} \\
\text { rats }\end{array}$ & $\begin{array}{l}\mathrm{CBF} \uparrow, \\
\text { spatial } \\
\text { memory } \\
\uparrow\end{array}$ & {$[37]$} \\
\hline Simvastatin & $\begin{array}{l}50 \\
\mathrm{mg} / \mathrm{kg}, \\
\text { p.o. }\end{array}$ & $\begin{array}{l}32 \\
\text { days }\end{array}$ & $\begin{array}{l}\text { MDA } \downarrow ; \\
\text { GSH } \uparrow\end{array}$ & $\begin{array}{l}\operatorname{AchE} \downarrow \\
\operatorname{Ach} \uparrow\end{array}$ & $\begin{array}{l}\text { IL-6 } \downarrow ; \text { IL-10 } \\
\uparrow\end{array}$ & & & $\begin{array}{l}\text { In vivo } \mathrm{L}- \\
\text { methionine } \\
\text { rats }\end{array}$ & $\begin{array}{l}\text { Learning } \\
\text { and } \\
\text { memory } \\
\uparrow\end{array}$ & {$[39]$} \\
\hline Melatonin & $\begin{array}{l}20 \\
\mu \mathrm{g} / \mathrm{ml}, \\
\text { i.g. }\end{array}$ & $\begin{array}{l}28 \\
\text { days }\end{array}$ & $\begin{array}{l}\text { TBARS } \\
\downarrow ; \text { GSH, } \\
\text { SOD, } \\
\text { CAT and } \\
\text { TAC } \uparrow\end{array}$ & $\operatorname{AchE} \downarrow$ & & $\begin{array}{l}\mathrm{Bax} / \mathrm{Bcl}- \\
2 \downarrow\end{array}$ & & $\begin{array}{l}\text { In vivo } 2 \mathrm{VO} \\
\text { rats }\end{array}$ & $\begin{array}{l}\text { Learning } \\
\text { and } \\
\text { memory } \\
\uparrow\end{array}$ & $\begin{array}{l}{[41,} \\
83]\end{array}$ \\
\hline SLT & $\begin{array}{l}50 \\
\mu \mathrm{g} / \mathrm{mL} ; \\
16.5 \\
\text { and } 33 \\
\mathrm{mg} / \mathrm{kg}, \\
\text { i.g. }\end{array}$ & $\begin{array}{l}24 \mathrm{~h} \\
28 \\
\text { days }\end{array}$ & $\begin{array}{l}\text { ROS } \downarrow ; \\
\text { SOD } \uparrow\end{array}$ & & $\begin{array}{l}\text { Glial } \\
\text { activation } \downarrow\end{array}$ & $\begin{array}{l}\mathrm{Bax} / \mathrm{Bcl}- \\
2 \downarrow ; \\
\text { caspase- } \\
3 \downarrow\end{array}$ & & $\begin{array}{l}\text { In vitro } \\
\text { EAhy926 } \\
\text { cells; In vivo } \\
2 \text { VO rats }\end{array}$ & No data & $\begin{array}{l}{[42,} \\
94]\end{array}$ \\
\hline ANF & $\begin{array}{l}10 \\
\mathrm{mg} / \mathrm{kg}, \\
\text { i.p. }\end{array}$ & 5 days & $\begin{array}{l}\text { TBARS } \\
\downarrow ; \text { GSH } \uparrow\end{array}$ & $\operatorname{AchE} \downarrow$ & & & & $\begin{array}{l}\text { In vivo } 4 \mathrm{VO} \\
\text { rats }\end{array}$ & $\begin{array}{l}\text { Learning } \\
\text { and } \\
\text { memory }\end{array}$ & {$[44]$} \\
\hline
\end{tabular}




\begin{tabular}{|c|c|c|c|c|c|c|c|c|c|c|}
\hline ICCB & $\begin{array}{l}\text { Flexible } \\
\text { dose }\end{array}$ & 6 days & $\begin{array}{l}\text { MDA } \downarrow ; \\
\text { SOD } \uparrow\end{array}$ & & & $\begin{array}{l}\mathrm{Bax} / \mathrm{Bcl}- \\
2 \downarrow\end{array}$ & & $\begin{array}{l}\text { In vivo } \\
\text { hyperlipemia } \\
\text { rats }\end{array}$ & $\begin{array}{l}\text { Learning } \\
\text { and } \\
\text { memory } \\
\uparrow\end{array}$ & {$[45]$} \\
\hline Resveratrol & $\begin{array}{l}\text { Flexible } \\
\text { dose }\end{array}$ & 7 days & $\begin{array}{l}\text { ROS } \downarrow \text {; } \\
\text { SOD } \uparrow\end{array}$ & $\operatorname{Ach} E \downarrow$ & & $\begin{array}{l}\mathrm{Bax} / \mathrm{Bcl}- \\
2 \downarrow ; \\
\text { caspase- } \\
3 \downarrow\end{array}$ & $\begin{array}{l}\text { PSD93,95 } \\
\uparrow ; \text { CREB } \\
\text { and } \\
\text { NR2A/B } \\
\uparrow\end{array}$ & $\begin{array}{l}\text { In vivo } 2 \mathrm{VO} \\
\text { rats }\end{array}$ & $\begin{array}{l}\text { Learning } \\
\text { and } \\
\text { memory } \\
\uparrow\end{array}$ & $\begin{array}{l}{[54,} \\
83 \\
129 \\
158]\end{array}$ \\
\hline Chitosan & $\begin{array}{l}375 \text { and } \\
700 \\
\mathrm{mg} / \mathrm{kg} \\
\text { i.g. }\end{array}$ & $\begin{array}{l}28 \\
\text { days }\end{array}$ & ROS $\downarrow$ & & $\begin{array}{l}\text { Glial } \\
\text { activation } \downarrow\end{array}$ & $\begin{array}{l}\text { Caspase- } \\
3 \downarrow\end{array}$ & & $\begin{array}{l}\text { In vivo } 2 \mathrm{VO} \\
\text { rats }\end{array}$ & $\begin{array}{l}\text { Learning } \\
\text { and } \\
\text { memory } \\
\uparrow\end{array}$ & {$[55]$} \\
\hline DM & $\begin{array}{l}\text { Flexible } \\
\text { dose }\end{array}$ & $\begin{array}{l}37 \\
\text { days }\end{array}$ & $\mathrm{SOD} \uparrow$ & & $\begin{array}{l}\text { Glial } \\
\text { activation } \downarrow\end{array}$ & & & $\begin{array}{l}\text { In vivo } 2 \mathrm{VO} \\
\text { rats }\end{array}$ & $\begin{array}{l}\text { Learning } \\
\text { and } \\
\text { memory } \\
\uparrow\end{array}$ & {$[56]$} \\
\hline PNC & $\begin{array}{l}5 \text { and } \\
10 \\
\mathrm{mg} / \mathrm{kg}, \\
\text { i.g. }\end{array}$ & $\begin{array}{l}35 \\
\text { days }\end{array}$ & $\begin{array}{l}\text { MDA } \downarrow ; \\
\text { GSH and } \\
\text { SOD } \uparrow\end{array}$ & & & $\begin{array}{l}\text { Caspase- } \\
3 \text { and }-9 \\
\downarrow\end{array}$ & & No data & $\begin{array}{l}\text { Learning } \\
\text { and } \\
\text { memory } \\
\uparrow\end{array}$ & {$[61]$} \\
\hline ST09 & $\begin{array}{l}3.5 \\
\mathrm{mg} / \mathrm{kg}, \\
\text { i.p. }\end{array}$ & $\begin{array}{l}42 \\
\text { days }\end{array}$ & $\begin{array}{l}\text { MDA } \downarrow ; \\
\text { SOD } \uparrow\end{array}$ & AchE $\downarrow$ & & & & $\begin{array}{l}\text { In vivo } 2 \mathrm{VO} \\
\text { rats }\end{array}$ & $\begin{array}{l}\text { Learning } \\
\text { and } \\
\text { memory } \\
\uparrow\end{array}$ & {$[82]$} \\
\hline F. mume & $\begin{array}{l}200 \\
\mathrm{mg} / \mathrm{kg}, \\
\text { i.g. }\end{array}$ & $\begin{array}{l}21 \text { to } \\
42 \\
\text { days }\end{array}$ & & $\mathrm{ChAT} \uparrow$ & $\begin{array}{l}\text { IL- } 1 \beta \text { and IL- } \\
6 \downarrow \text {; glial } \\
\text { activation } \downarrow\end{array}$ & & & $\begin{array}{l}\text { In vivo } 2 \mathrm{VO} \\
\text { rats }\end{array}$ & $\begin{array}{l}\text { Learning } \\
\text { and } \\
\text { memory } \\
\uparrow\end{array}$ & [93] \\
\hline WIN & $\begin{array}{l}1 \\
\mathrm{mg} / \mathrm{kg}, \\
\text { i.p. }\end{array}$ & $\begin{array}{l}28 \\
\text { days }\end{array}$ & & & $\begin{array}{l}\text { IL- } 1 \beta \text { and } \\
\text { TNF- } \alpha \downarrow\end{array}$ & $\begin{array}{l}\text { Caspase- } \\
3 \text { and }-3 \\
\downarrow\end{array}$ & & $\begin{array}{l}\text { In vivo } 2 \mathrm{VO} \\
\text { rats }\end{array}$ & $\begin{array}{l}\text { Learning } \\
\text { and } \\
\text { memory } \\
\uparrow\end{array}$ & [98] \\
\hline PF & $\begin{array}{l}\text { Flexible } \\
\text { dose }\end{array}$ & $\begin{array}{l}28 \\
\text { days }\end{array}$ & & & $\begin{array}{l}\text { IL-1 } \beta, \text { IL- } 6 \\
\text { and TNF- } \alpha \downarrow\end{array}$ & $\begin{array}{l}\text { Bax/Bcl- } \\
2 \downarrow ; \\
\text { caspase- } \\
3 \downarrow\end{array}$ & & $\begin{array}{l}\text { In vivo } 2 \mathrm{VO} \\
\text { rats }\end{array}$ & $\begin{array}{l}\mathrm{CBF} \uparrow \text {, } \\
\text { learning } \\
\text { and } \\
\text { memory } \\
\uparrow\end{array}$ & $\begin{array}{l}{[99,} \\
100, \\
146]\end{array}$ \\
\hline Carnosine & $\begin{array}{l}200 \text { and } \\
500 \\
\mathrm{mg} / \mathrm{kg}, \\
\text { i.p. }\end{array}$ & $\begin{array}{l}37 \\
\text { days }\end{array}$ & $\begin{array}{l}\text { TBARS } \\
\downarrow ; \text { GSH } \uparrow\end{array}$ & $A \operatorname{chE} \downarrow$ & $\begin{array}{l}\text { Glia } \\
\text { activation } \downarrow\end{array}$ & & & $\begin{array}{l}\text { In vivo } 2 \mathrm{VO} \\
\text { rats }\end{array}$ & $\begin{array}{l}\text { Learning } \\
\text { and } \\
\text { memory } \\
\uparrow\end{array}$ & [105] \\
\hline $\operatorname{Re} A$ & $\begin{array}{l}40 \text { and } \\
80 \\
\mathrm{mg} / \mathrm{kg}, \\
\text { i.p. }\end{array}$ & $\begin{array}{l}14 \\
\text { days }\end{array}$ & ROS $\downarrow$ & & $\begin{array}{l}\text { IL-1 } \beta, \text { IL- } 6 \\
\text { and TNF- } \alpha \downarrow\end{array}$ & $\begin{array}{l}\text { Caspase- } \\
3 \downarrow\end{array}$ & & $\begin{array}{l}\text { In vivo } 2 \mathrm{VO} \\
\text { rats }\end{array}$ & $\begin{array}{l}\text { Learning } \\
\text { and } \\
\text { memory } \\
\uparrow\end{array}$ & [122] \\
\hline L-NBP & $\begin{array}{l}15 \\
\mathrm{mg} / \mathrm{kg}, \\
\text { i.g. }\end{array}$ & $\begin{array}{l}20 \\
\text { days }\end{array}$ & ROS $\downarrow$ & & & $\begin{array}{l}\text { Bax/Bcl- } \\
2 \downarrow\end{array}$ & & $\begin{array}{l}\text { In vitro } \mathrm{HT} 22 \\
\text { cell; in vivo } \\
2 \mathrm{VO} \text { rats }\end{array}$ & $\begin{array}{l}\text { Learning } \\
\text { and } \\
\text { memory } \\
\uparrow\end{array}$ & [140] \\
\hline ORC & $\begin{array}{l}100 \text { and } \\
200 \\
\mathrm{mg} / \mathrm{kg}, \\
\text { i.g. }\end{array}$ & $\begin{array}{l}28 \\
\text { days }\end{array}$ & & & & $\begin{array}{l}\mathrm{Bax} / \mathrm{Bcl}- \\
2 \downarrow\end{array}$ & & $\begin{array}{l}\text { In vivo } 2 \mathrm{VO} \\
\text { rats }\end{array}$ & $\begin{array}{l}\text { Learning } \\
\text { and } \\
\text { memory } \\
\uparrow\end{array}$ & [148] \\
\hline ET & $\begin{array}{l}20 \\
\mathrm{mg} / \mathrm{kg}, \\
\text { i.g. }\end{array}$ & 7 days & $\begin{array}{l}\text { MDA } \downarrow ; \\
\text { SOD } \uparrow\end{array}$ & & & $\begin{array}{l}\text { Bax/Bcl- } \\
2 \downarrow\end{array}$ & $\begin{array}{l}\text { CaMKII, } \\
\text { NR2B } \\
\text { and } \\
\text { PSD95 } \uparrow\end{array}$ & $\begin{array}{l}\text { In vivo } 2 \mathrm{VO} \\
\text { rats }\end{array}$ & $\begin{array}{l}\text { Learning } \\
\text { and } \\
\text { memory } \\
\uparrow\end{array}$ & [156] \\
\hline CBL & $\begin{array}{l}2.5 \\
\mathrm{ml} / \mathrm{kg} \\
\text { i.p. }\end{array}$ & $\begin{array}{l}28 \\
\text { days }\end{array}$ & & & & $\begin{array}{l}\text { Bax/Bcl- } \\
2 \downarrow\end{array}$ & $\begin{array}{l}\mathrm{p}-\mathrm{CREB} \\
\text { and } \\
\text { PSD95 } \uparrow\end{array}$ & $\begin{array}{l}\text { In vivo } 2 \mathrm{VO} \\
\text { rats }\end{array}$ & $\begin{array}{l}\text { Learning } \\
\text { and } \\
\text { memory } \\
\uparrow\end{array}$ & [159] \\
\hline
\end{tabular}

i.v., intravenous; i.p., intraperitoneal; i.g., intragastric; $2 \mathrm{VO}, 2$-vessel occlusion; CBF, cerebral blood flow

Etidronate (ET) administration regulates $\mathrm{Ca}^{2+}$ CaMKII subsequently improves LTP induction. activities, such that $\mathrm{Ca}^{2+}$ enters the postsynaptic Moreover, the expression of LTP-related factors, membrane via NR2B receptor activation and $p$ - CaMKII, NR2B, and PSD95, is increased by ET 
administration [156]. In addition, the administration of neuronal gastrin-releasing peptide (GRP) significantly alleviates the cognitive deficits, restores damaged synaptic plasticity, and elevates the expression of the synaptic proteins, synaptophysin (SYP) and CaMKII [155].

The administration of vitamin B6 has been reported to enhance cognitive functions in $\mathrm{VaD}$ rats. Additionally, vitamin B 6 administration elevates the expression of NR2B, postsynaptic densities (PSDs) protein 95, and CaMKII, which is reduced in the hippocampus of $\mathrm{VaD}$ rats. The positive effects of vitamin $\mathrm{B} 6$ against $\mathrm{VaD}$ are related to the activation of NR2B-dependent PSD50/CaMKII signaling [157]. Additionally, resveratrol, a natural phenolic compound, alleviates cognitive deficits in $\mathrm{CCH}$ induced $\mathrm{VaD}$ rats. Administration of resveratrol enhances LTP induction and rescues the loss of dendritic spine and synaptic proteins, possibly via protein kinase A (PKA)/cAMP-responsive elementbinding protein (CREB) signaling activation [158]. Cerebrolysin (CBL), a peptide preparation derived from the porcine brain, has beneficial properties similar to those of endogenous neurotrophic factors. Administration of CBL markedly elevates the levels of synaptic proteins, such as PSD95, protein kinase $\mathrm{C}$ subunit gamma $(\mathrm{PKC} \gamma)$, and $\mathrm{p}-\mathrm{CREB}$, indicating that CBL may alleviate cognitive dysfunction by restoring synaptic plasticity [159]. Additionally, BDNF plays an important role in synaptic plasticity. BDNF can induce LTP and is closely associated with learning and memory processes [160]. Hydroxysafflor yellow A (HYSA), a mixture containing water-soluble chalcones, is a natural pigment of the safflower, Carthamus tinctorius $L$. [161]. HSYA may enhance the levels of BDNF and NR2B, improve LTP at CA3-CA1 synapses in the hippocampus, and alleviate cognitive deficits in $\mathrm{VaD}$ rats [162]. The above research results show that pharmacological therapies targeting synaptic plasticity have significant prospects in treating cognitive impairments in $\mathrm{VaD}$.

\section{Conclusion and Prospects}

In summary, since $\mathrm{VaD}$ is a neurodegenerative disease characterized by progressive cognitive decline, the ideal drug should be able to prevent or delay the development of $\mathrm{VaD}$. At present, there is not much controversy regarding the fact that $\mathrm{VaD}$ is a combined outcome of various pathophysiological changes (such as oxidative stress, central cholinergic system dysfunction, neuroinflammation, neuronal apoptosis, and synaptic plasticity dysfunction) induced by $\mathrm{CCH}$. In this review, we found that many drugs that are beneficial to $\mathrm{VaD}$ and the underlying molecular mechanisms target two or more of the aforementioned pathophysiological changes (Table 1). Therefore, drugs aimed at multiple pathophysiological factors may be the future direction in $\mathrm{VaD}$ treatment. In addition, we found that natural drugs have been shown to improve cognitive impairments in $\mathrm{VaD}$ through a variety of means; their targets and mechanisms were far more complex than those for a single chemical. However, most drugs are still in the basic research stage; thus, it is necessary to attentively await research experiments at the clinical stage in the future.

\section{Acknowledgments}

The work was supported by the National Natural Science Foundation of China (81660151, 81660751).

\section{Declaration of interest}

The authors declare no conflict of interest.

\section{References}

[1] Wu YT, Fratiglioni L, Matthews FE, Lobo A, Breteler MM, Skoog I, et al. (2016). Dementia in western Europe: epidemiological evidence and implications for policy making. Lancet Neurol, 15:116-124.

[2] Wolters FJ, Ikram MA (2019). Epidemiology of Vascular Dementia. Arterioscler Thromb Vasc Biol, 39:1542-1549.

[3] Jia L, Quan M, Fu Y, Zhao T, Li Y, Wei C, et al. (2020). Dementia in China: epidemiology, clinical management, and research advances. Lancet Neurol, 19:81-92.

[4] Chan KY, Wang W, Wu JJ, Liu L, Theodoratou E, Car $\mathrm{J}$, et al. (2013). Epidemiology of Alzheimer's disease and other forms of dementia in China, 1990-2010: a systematic review and analysis. Lancet, 381:20162023.

[5] Sachdev PS, Blacker D, Blazer DG, Ganguli M, Jeste DV, Paulsen JS, et al. (2014). Classifying neurocognitive disorders: the DSM-5 approach. Nat Rev Neurol, 10:634-642.

[6] First MB (2009). Harmonisation of ICD-11 and DSM$\mathrm{V}$ : opportunities and challenges. $\mathrm{Br} \mathrm{J}$ Psychiatry, 195:382-390.

[7] Sachdev P, Kalaria R, O'Brien J, Skoog I, Alladi S, Black SE, et al. (2014). Diagnostic criteria for vascular cognitive disorders: a VASCOG statement. Alzheimer Dis Assoc Disord, 28:206-218.

[8] Chui HC, Victoroff JI, Margolin D, Jagust W, Shankle R, Katzman R (1992). Criteria for the diagnosis of ischemic vascular dementia proposed by the State of California Alzheimer's Disease Diagnostic and 
Treatment Centers. Neurology, 42:473-480.

[9] Román GC, Tatemichi TK, Erkinjuntti T, Cummings JL, Masdeu JC, Garcia JH, et al. (1993). Vascular dementia: diagnostic criteria for research studies. Report of the NINDS-AIREN International Workshop. Neurology, 43:250-260.

[10] Wetterling T, Kanitz RD, Borgis KJ (1996). Comparison of different diagnostic criteria for vascular dementia (ADDTC, DSM-IV, ICD-10, NINDS-AIREN). Stroke, 27:30-36.

[11] Moroney JT, Bagiella E, Desmond DW, Hachinski VC, Mölsä PK, Gustafson L, et al. (1997). Meta-analysis of the Hachinski Ischemic Score in pathologically verified dementias. Neurology, 49:1096-1105.

[12] Xu X, Wang B, Ren C, Hu J, Greenberg DA, Chen T, et al. (2017). Recent Progress in Vascular Aging: Mechanisms and Its Role in Age-related Diseases. Aging Dis, 8:486-505.

[13] Wardlaw JM, Smith C, Dichgans M (2019). Small vessel disease: mechanisms and clinical implications. Lancet Neurol, 18:684-696.

[14] Iadecola C (2013). The pathobiology of vascular dementia. Neuron, 80:844-866.

[15] Kalaria RN (2018). The pathology and pathophysiology of vascular dementia. Neuropharmacology, 134:226-239.

[16] Du SQ, Wang XR, Xiao LY, Tu JF, Zhu W, He T, et al. (2017). Molecular Mechanisms of Vascular Dementia: What Can Be Learned from Animal Models of Chronic Cerebral Hypoperfusion? Mol Neurobiol, 54:3670-3682.

[17] Iadecola C, Duering M, Hachinski V, Joutel A, Pendlebury ST, Schneider JA, et al. (2019). Vascular Cognitive Impairment and Dementia: JACC Scientific Expert Panel. J Am Coll Cardiol, 73:3326-3344.

[18] Calabrese V, Giordano J, Signorile A, Laura Ontario M, Castorina S, De Pasquale C, et al. (2016). Major pathogenic mechanisms in vascular dementia: Roles of cellular stress response and hormesis in neuroprotection. J Neurosci Res, 94:1588-1603.

[19] Martinez MA, Rodriguez JL, Lopez-Torres B, Martinez M, Martinez-Larranaga MR, Maximiliano JE, et al. (2020). Use of human neuroblastoma SHSY5Y cells to evaluate glyphosate-induced effects on oxidative stress, neuronal development and cell death signaling pathways. Environ Int, 135:105414.

[20] Zhang T, Gu J, Wu L, Li N, Sun Y, Yu P, et al. (2017). Neuroprotective and axonal outgrowth-promoting effects of tetramethylpyrazine nitrone in chronic cerebral hypoperfusion rats and primary hippocampal neurons exposed to hypoxia. Neuropharmacology, 118:137-147.

[21] Packer L, Tritschler HJ (1996). Alpha-lipoic acid: the metabolic antioxidant. Free Radic Biol Med, 20:625626.

[22] Zhao RR, Xu F, Xu XC, Tan GJ, Liu LM, Wu N, et al. (2015). Effects of alpha-lipoic acid on spatial learning and memory, oxidative stress, and central cholinergic system in a rat model of vascular dementia. Neurosci Lett, 587:113-119.
Nie C, Nie H, Zhao Y, Wu J, Zhang X (2016). Betaine reverses the memory impairments in a chronic cerebral hypoperfusion rat model. Neurosci Lett, 615:9-14.

Kaundal M, Zameer S, Najmi AK, Parvez S, Akhtar M (2018). Betulinic acid, a natural PDE inhibitor restores hippocampal cAMP/cGMP and BDNF, improve cerebral blood flow and recover memory deficits in permanent BCCAO induced vascular dementia in rats. Eur J Pharmacol, 832:56-66.

Strehlow K, Rotter S, Wassmann S, Adam O, Grohe C, Laufs K, et al. (2003). Modulation of antioxidant enzyme expression and function by estrogen. Circ Res, 93:170-177.

Behl C, Skutella T, Lezoualc'h F, Post A, Widmann M, Newton CJ, et al. (1997). Neuroprotection against oxidative stress by estrogens: structure-activity relationship. Mol Pharmacol, 51:535-541.

Verma A, Sharma S (2015). Beneficial Effect of Protein Tyrosine Phosphatase Inhibitor and Phytoestrogen in Dyslipidemia-Induced Vascular Dementia in Ovariectomized Rats. J Stroke Cerebrovasc Dis, 24:2434-2446.

Casado A, Encarnacion Lopez-Fernandez M, Concepcion Casado M, de La Torre R (2008). Lipid peroxidation and antioxidant enzyme activities in vascular and Alzheimer dementias. Neurochem Res, 33:450-458.

Liu H, Zhang J (2012). Cerebral hypoperfusion and cognitive impairment: the pathogenic role of vascular oxidative stress. Int J Neurosci, 122:494-499.

Forette F, Seux ML, Staessen JA, Thijs L, Birkenhager WH, Babarskiene MR, et al. (1998). Prevention of dementia in randomised double-blind placebocontrolled Systolic Hypertension in Europe (Syst-Eur) trial. Lancet, 352:1347-1351.

Skoog I, Lernfelt B, Landahl S, Palmertz B, Andreasson LA, Nilsson L, et al. (1996). 15-year longitudinal study of blood pressure and dementia. Lancet, 347:1141-1145.

Oishi E, Ohara T, Sakata S, Fukuhara M, Hata J, Yoshida D, et al. (2017). Day-to-Day Blood Pressure Variability and Risk of Dementia in a General Japanese Elderly Population: The Hisayama Study. Circulation, 136:516-525.

Liu TH, Chiou J, Tsai TY (2016). Effects of Lactobacillus plantarum TWK10-Fermented Soymilk on Deoxycorticosterone Acetate-Salt-Induced Hypertension and Associated Dementia in Rats. Nutrients, 8.

Jayant S, Sharma B (2016). Selective Modulator of Cannabinoid Receptor Type 2 Reduces Memory Impairment and Infarct Size During Cerebral Hypoperfusion and Vascular Dementia. Curr Neurovasc Res, 13:289-302.

Ueno Y, Zhang N, Miyamoto N, Tanaka R, Hattori N, Urabe $T$ (2009). Edaravone attenuates white matter lesions through endothelial protection in a rat chronic hypoperfusion model. Neuroscience, 162:317-327.

Liao L, Shi J, Jiang C, Zhang L, Feng L, Liu J, et al. (2019). Activation of anti-oxidant of curcumin 
pyrazole derivatives through preservation of mitochondria function and $\mathrm{Nrf} 2$ signaling pathway. Neurochem Int, 125:82-90.

[37] Li X, Lu F, Li W, Qin L, Yao Y, Ge X, et al. (2017). Edaravone injection reverses learning and memory deficits in a rat model of vascular dementia. Acta Biochim Biophys Sin (Shanghai), 49:83-89.

[38] Abbas AM, Sakr HF (2013). Simvastatin and vitamin E effects on cardiac and hepatic oxidative stress in rats fed on high fat diet. J Physiol Biochem, 69:737-750.

[39] El-Dessouki AM, Galal MA, Awad AS, Zaki HF (2017). Neuroprotective Effects of Simvastatin and Cilostazol in L-Methionine-Induced Vascular Dementia in Rats. Mol Neurobiol, 54:5074-5084.

[40] Ozacmak VH, Barut F, Ozacmak HS (2009). Melatonin provides neuroprotection by reducing oxidative stress and HSP70 expression during chronic cerebral hypoperfusion in ovariectomized rats. J Pineal Res, 47:156-163.

[41] Bin-Jaliah I, Sakr HF (2018). Melatonin ameliorates brain oxidative stress and upregulates senescence marker protein-30 and osteopontin in a rat model of vascular dementia. Physiol Int, 105:38-52.

[42] Seto SW, Chang D, Ko WM, Zhou X, Kiat H, Bensoussan A, et al. (2017). Sailuotong Prevents Hydrogen Peroxide $(\mathrm{H}(2) \mathrm{O}(2))$-Induced Injury in EA.hy926 Cells. Int J Mol Sci, 18.

[43] Liu FX, Niu K, Wu ZG, Xue GP, Yang JM, Zhang DS (2015). [Effects of Jiji decoction on the cognitive function and oxidative stress in mice with vascular dementia induced by cerebral ischemia/reperfusion]. Zhongguo Ying Yong Sheng Li Xue Za Zhi, 31:170173, 177.

[44] Rishitha N, Muthuraman A (2020). Preventative effects of alpha-naphtho flavone in vascular dementia. Front Biosci (Elite Ed), 12:79-94.

[45] Zhong XM, Ren XC, Lou YL, Chen MJ, Li GZ, Gong $X Y$, et al. (2016). Effects of in-vitro cultured calculus bovis on learning and memory impairments of hyperlipemia vascular dementia rats. J Ethnopharmacol, 192:390-397.

[46] Zhang Y, Miao L, Lin L, Ren CY, Liu JX, Cui YM (2018). Repeated administration of Sailuotong, a fixed combination of Panax ginseng, Ginkgo biloba, and Crocus sativus extracts for vascular dementia, alters CYP450 activities in rats. Phytomedicine, 38:125-134.

[47] Liang J, Li F, Wei C, Song H, Wu L, Tang Y, et al. (2014). Rationale and design of a multicenter, phase 2 clinical trial to investigate the efficacy of traditional Chinese medicine SaiLuoTong in vascular dementia. J Stroke Cerebrovasc Dis, 23:2626-2634.

[48] Jia J, Wei C, Chen S, Li F, Tang Y, Qin W, et al. (2018). Efficacy and safety of the compound Chinese medicine SaiLuoTong in vascular dementia: A randomized clinical trial. Alzheimers Dement (N Y), 4:108-117.

[49] Ali T, Kim T, Rehman SU, Khan MS, Amin FU, Khan M, et al. (2018). Natural Dietary Supplementation of Anthocyanins via PI3K/Akt/Nrf2/HO-1 Pathways Mitigate Oxidative Stress, Neurodegeneration, and
Memory Impairment in a Mouse Model of Alzheimer's Disease. Mol Neurobiol, 55:6076-6093.

[50] Wei CC, Kong YY, Li GQ, Guan YF, Wang P, Miao CY (2017). Nicotinamide mononucleotide attenuates brain injury after intracerebral hemorrhage by activating Nrf2/HO-1 signaling pathway. Sci Rep, 7:717.

Ishii T, Itoh $\mathrm{K}$, Takahashi S, Sato $\mathrm{H}$, Yanagawa $\mathrm{T}$, Katoh Y, et al. (2000). Transcription factor Nrf2 coordinately regulates a group of oxidative stressinducible genes in macrophages. J Biol Chem, 275:16023-16029.

[52] Tu W, Wang H, Li S, Liu Q, Sha H (2019). The AntiInflammatory and Anti-Oxidant Mechanisms of the Keap1/Nrf2/ARE Signaling Pathway in Chronic Diseases. Aging Dis, 10:637-651.

[53] Zhang D, Xiao Y, Lv P, Teng Z, Dong Y, Qi Q, et al. (2018). Edaravone attenuates oxidative stress induced by chronic cerebral hypoperfusion injury: role of ERK/Nrf2/HO-1 signaling pathway. Neurol Res, 40:110.

[54] Yadav A, Sunkaria A, Singhal N, Sandhir R (2018). Resveratrol loaded solid lipid nanoparticles attenuate mitochondrial oxidative stress in vascular dementia by activating Nrf2/HO-1 pathway. Neurochem Int, 112:239-254.

[55] Jiang P, Chen L, Sun J, Li J, Xu J, Liu W, et al. (2019). Chotosan ameliorates cognitive impairment and hippocampus neuronal loss in experimental vascular dementia via activating the Nrf2-mediated antioxidant pathway. J Pharmacol Sci, 139:105-111.

[56] Xu X, Zhang B, Lu K, Deng J, Zhao F, Zhao BQ, et al. (2016). Prevention of Hippocampal Neuronal Damage and Cognitive Function Deficits in Vascular Dementia by Dextromethorphan. Mol Neurobiol, 53:3494-3502. Andreadi CK, Howells LM, Atherfold PA, Manson MM (2006). Involvement of Nrf2, p38, B-Raf, and nuclear factor-kappaB, but not phosphatidylinositol 3kinase, in induction of hemeoxygenase-1 by dietary polyphenols. Mol Pharmacol, 69:1033-1040.

[58] Lee YS, Park SY, Heo HJ, Lee WS, Hong KW, Kim CD (2019). Multitarget-directed cotreatment with cilostazol and aripiprazole for augmented neuroprotection against oxidative stress-induced toxicity in HT22 mouse hippocampal cells. Eur J Pharmacol, 857:172454.

[59] Abramov AY, Jacobson J, Wientjes F, Hothersall J, Canevari L, Duchen MR (2005). Expression and modulation of an NADPH oxidase in mammalian astrocytes. J Neurosci, 25:9176-9184.

[60] Liu WY, Liou SS, Hong TY, Liu IM (2017). Protective Effects of Hesperidin (Citrus Flavonone) on High Glucose Induced Oxidative Stress and Apoptosis in a Cellular Model for Diabetic Retinopathy. Nutrients, 9.

[61] Liu H, Zhao M, Yang S, Gong DR, Chen DZ, Du DY (2015). (2R,3S)-Pinobanksin-3-cinnamate improves cognition and reduces oxidative stress in rats with vascular dementia. J Nat Med, 69:358-365.

[62] Hampel H, Mesulam MM, Cuello AC, Farlow MR, Giacobini E, Grossberg GT, et al. (2018). The 
cholinergic system in the pathophysiology and treatment of Alzheimer's disease. Brain, 141:19171933.

[63] Graham WV, Bonito-Oliva A, Sakmar TP (2017). Update on Alzheimer's Disease Therapy and Prevention Strategies. Annu Rev Med, 68:413-430.

[64] Sohn E, Kim YJ, Lim HS, Kim BY, Jeong SJ (2019). Hwangryunhaedok-Tang Exerts Neuropreventive Effect on Memory Impairment by Reducing Cholinergic System Dysfunction and Inflammatory Response in a Vascular Dementia Rat Model. Molecules, 24.

[65] McShane R, Westby MJ, Roberts E, Minakaran N, Schneider L, Farrimond LE, et al. (2019). Memantine for dementia. Cochrane Database Syst Rev, 3:Cd003154.

[66] Wilkinson D, Doody R, Helme R, Taubman K, Mintzer J, Kertesz A, et al. (2003). Donepezil in vascular dementia: a randomized, placebo-controlled study. Neurology, 61:479-486.

[67] Roman GC, Salloway S, Black SE, Royall DR, Decarli C, Weiner MW, et al. (2010). Randomized, placebocontrolled, clinical trial of donepezil in vascular dementia: differential effects by hippocampal size. Stroke, 41:1213-1221.

[68] Roman GC, Wilkinson DG, Doody RS, Black SE, Salloway SP, Schindler RJ (2005). Donepezil in vascular dementia: combined analysis of two largescale clinical trials. Dement Geriatr Cogn Disord, 20:338-344.

[69] Dichgans M, Markus HS, Salloway S, Verkkoniemi A, Moline M, Wang Q, et al. (2008). Donepezil in patients with subcortical vascular cognitive impairment: a randomised double-blind trial in CADASIL. Lancet Neurol, 7:310-318.

[70] Black S, Roman GC, Geldmacher DS, Salloway S, Hecker J, Burns A, et al. (2003). Efficacy and tolerability of donepezil in vascular dementia: positive results of a 24-week, multicenter, international, randomized, placebo-controlled clinical trial. Stroke, 34:2323-2330.

[71] Small G, Erkinjuntti T, Kurz A, Lilienfeld S (2003). Galantamine in the treatment of cognitive decline in patients with vascular dementia or Alzheimer's disease with cerebrovascular disease. CNS Drugs, 17:905-914.

[72] Kurz AF, Erkinjuntti T, Small GW, Lilienfeld S, Damaraju CR (2003). Long-term safety and cognitive effects of galantamine in the treatment of probable vascular dementia or Alzheimer's disease with cerebrovascular disease. Eur J Neurol, 10:633-640.

[73] Erkinjuntti T, Kurz A, Gauthier S, Bullock R, Lilienfeld S, Damaraju CV (2002). Efficacy of galantamine in probable vascular dementia and Alzheimer's disease combined with cerebrovascular disease: a randomised trial. Lancet, 359:1283-1290.

[74] Auchus AP, Brashear HR, Salloway S, Korczyn AD, De Deyn PP, Gassmann-Mayer C (2007). Galantamine treatment of vascular dementia: a randomized trial. Neurology, 69:448-458.

[75] Moretti R, Torre P, Antonello RM, Cazzato G, Griggio
S, Ukmar M, et al. (2004). Rivastigmine superior to aspirin plus nimodipine in subcortical vascular dementia: an open, 16-month, comparative study. Int J Clin Pract, 58:346-353.

[76] Moretti R, Torre P, Antonello RM, Cazzato G (2001). Rivastigmine in subcortical vascular dementia: a comparison trial on efficacy and tolerability for 12 months follow-up. Eur J Neurol, 8:361-362.

[77] Moretti R, Torre P, Antonello RM, Cattaruzza T, Cazzato G (2004). Cholinesterase inhibition as a possible therapy for delirium in vascular dementia: a controlled, open 24-month study of 246 patients. Am J Alzheimers Dis Other Demen, 19:333-339.

[78] Lojkowska W, Ryglewicz D, Jedrzejczak T, Minc S, Jakubowska T, Jarosz H, et al. (2003). The effect of cholinesterase inhibitors on the regional blood flow in patients with Alzheimer's disease and vascular dementia. J Neurol Sci, 216:119-126.

[79] Lanner JT (2012). Ryanodine receptor physiology and its role in disease. Adv Exp Med Biol, 740:217-234.

[80] Singh P, Sharma B (2016). Reversal in Cognition Impairments, Cholinergic Dysfunction, and Cerebral Oxidative Stress Through the Modulation of Ryanodine Receptors (RyRs) and Cysteinyl Leukotriene-1 (CysLT1) Receptors. Curr Neurovasc Res, 13:10-21.

[81] Shin NR, Ko JW, Park SH, Cho YK, Oh SR, Ahn KS, et al. (2017). Protective effect of HwangRyunHaeDokTang water extract against chronic obstructive pulmonary disease induced by cigarette smoke and lipopolysaccharide in a mouse model. J Ethnopharmacol, 200:60-65.

[82] Liu JM, Wu PF, Rao J, Zhou J, Shen ZC, Luo H, et al. (2016). ST09, a Novel Thioester Derivative of Tacrine, Alleviates Cognitive Deficits and Enhances Glucose Metabolism in Vascular Dementia Rats. CNS Neurosci Ther, 22:220-229.

[83] Shen D, Tian X, Sang W, Song R (2016). Effect of Melatonin and Resveratrol against Memory Impairment and Hippocampal Damage in a Rat Model of Vascular Dementia. Neuroimmunomodulation, 23:318-331.

[84] Gao Y, Li W, Liu Y, Wang Y, Zhang J, Li M, et al. (2018). Effect of Telmisartan on Preventing Learning and Memory Deficits Via Peroxisome ProliferatorActivated Receptor-gamma in Vascular Dementia Spontaneously Hypertensive Rats. J Stroke Cerebrovasc Dis, 27:277-285.

[85] Choi BR, Kwon KJ, Park SH, Jeon WK, Han SH, Kim HY, et al. (2011). Alternations of Septal-hippocampal System in the Adult Wistar Rat with Spatial Memory Impairments Induced by Chronic Cerebral Hypoperfusion. Exp Neurobiol, 20:92-99.

[86] Li J, Zhang L, Li JJ, Xian Q, Chen L, Li DY, et al. (2017). Effects of estrogen on learning-memory and expression of calbindin-D28K in hippocampus in vascular dementia rats. Pak J Pharm Sci, 30:14031406.

[87] Tang H, Zhang W, Zhu Y, Zhang X, Wang R (2015). [Estrogen decreases vascular damage induced by 
chronic hypoperfusion through upregulating VEGF expression]. Nan Fang Yi Ke Da Xue Xue Bao, 35:1552-1556.

[88] Jia Z, Xue R, Ma S, Xu J, Guo S, Li S, et al. (2016). Erythropoietin Attenuates the Memory Deficits in Aging Rats by Rescuing the Oxidative Stress and Inflammation and Promoting BDNF Releasing. Mol Neurobiol, 53:5664-5670.

[89] Wang R, Li J, Duan Y, Tao Z, Zhao H, Luo Y (2017). Effects of Erythropoietin on Gliogenesis during Cerebral Ischemic/Reperfusion Recovery in Adult Mice. Aging Dis, 8:410-419.

[90] Ma S, Chen J, Chen C, Wei N, Xu J, Yang G, et al. (2018). Erythropoietin Rescues Memory Impairment in a Rat Model of Chronic Cerebral Hypoperfusion via the EPO-R/JAK2/STAT5/PI3K/Akt/GSK-3beta Pathway. Mol Neurobiol, 55:3290-3299.

[91] Kim MS, Jeon WK, Lee KW, Park YH, Han JS (2015). Ameliorating Effects of Ethanol Extract of Fructus mume on Scopolamine-Induced Memory Impairment in Mice. Evid Based Complement Alternat Med, 2015:102734

[92] Jeon WK, Ma J, Choi BR, Han SH, Jin Q, Hwang BY, et al. (2012). Effects of Fructus mume Extract on MAPK and NF-kappaB Signaling and the Resultant Improvement in the Cognitive Deficits Induced by Chronic Cerebral Hypoperfusion. Evid Based Complement Alternat Med, 2012:450838.

[93] Kim MS, Bang JH, Lee J, Han JS, Kang HW, Jeon WK (2016). Fructus mume Ethanol Extract Prevents Inflammation and Normalizes the Septohippocampal Cholinergic System in a Rat Model of Chronic Cerebral Hypoperfusion. J Med Food, 19:196-204.

[94] Zhang Y, Liu J, Yao M, Song W, Zheng Y, Xu L, et al. (2019). Sailuotong Capsule Prevents the Cerebral Ischaemia-Induced Neuroinflammation and Impairment of Recognition Memory through Inhibition of LCN2 Expression. Oxid Med Cell Longev, 2019:8416105.

[95] Belkhelfa M, Beder N, Mouhoub D, Amri M, Hayet R, Tighilt N, et al. (2018). The involvement of neuroinflammation and necroptosis in the hippocampus during vascular dementia. J Neuroimmunol, 320:48-57.

[96] Sun J, Fang YQ, Ren H, Chen T, Guo JJ, Yan J, et al. (2013). WIN55,212-2 protects oligodendrocyte precursor cells in stroke penumbra following permanent focal cerebral ischemia in rats. Acta Pharmacol Sin, 34:119-128.

[97] Escamilla-Ramirez A, Garcia E, Palencia-Hernandez G, Colin-Gonzalez AL, Galvan-Arzate S, Tunez I, et al. (2017). URB597 and the Cannabinoid WIN55,2122 Reduce Behavioral and Neurochemical Deficits Induced by MPTP in Mice: Possible Role of Redox Modulation and NMDA Receptors. Neurotox Res, 31:532-544.

[98] Wang DP, Yin H, Kang K, Lin Q, Su SH, Hai J (2018). The potential protective effects of cannabinoid receptor agonist WIN55,212-2 on cognitive dysfunction is associated with the suppression of autophagy and inflammation in an experimental model of vascular dementia. Psychiatry Res, 267:281-288.

[99] Luo XQ, Li A, Yang X, Xiao X, Hu R, Wang TW, et al. (2018). Paeoniflorin exerts neuroprotective effects by modulating the M1/M2 subset polarization of microglia/macrophages in the hippocampal CA1 region of vascular dementia rats via cannabinoid receptor 2. Chin Med, 13:14.

[100] Zhang LG, Wang LJ, Shen QQ, Wang HF, Zhang Y, Shi CG, et al. (2017). Paeoniflorin improves regional cerebral blood flow and suppresses inflammatory factors in the hippocampus of rats with vascular dementia. Chin J Integr Med, 23:696-702.

[101] Cai M, Lee JH, Yang EJ (2017). Bee Venom Ameliorates Cognitive Dysfunction Caused by Neuroinflammation in an Animal Model of Vascular Dementia. Mol Neurobiol, 54:5952-5960.

[102] Zhang LY, Pan J, Mamtilahun M, Zhu Y, Wang L, Venkatesh A, et al. (2020). Microglia exacerbate white matter injury via complement $\mathrm{C} 3 / \mathrm{C} 3 \mathrm{aR}$ pathway after hypoperfusion. Theranostics, 10:74-90.

[103] Kim JH, Ko PW, Lee HW, Jeong JY, Lee MG, Kim JH, et al. (2017). Astrocyte-derived lipocalin-2 mediates hippocampal damage and cognitive deficits in experimental models of vascular dementia. Glia, 65:1471-1490.

[104] Feng X, Peng Y, Liu M, Cui L (2012). DL-3-nbutylphthalide extends survival by attenuating glial activation in a mouse model of amyotrophic lateral sclerosis. Neuropharmacology, 62:1004-1010.

[105] Ma J, Xiong JY, Hou WW, Yan HJ, Sun Y, Huang SW, et al. (2012). Protective effect of carnosine on subcortical ischemic vascular dementia in mice. CNS Neurosci Ther, 18:745-753.

[106] Li J, Ma YY, Liu B, Mao WJ, Zhang JX, Li SY (2016). [Effect of Yangxue Qingnao Granule on the Expression of CD11b in CA1 Region of Hippocampus of Vascular Dementia Rats]. Zhongguo Zhong Xi Yi Jie He Za Zhi, 36:619-623.

[107] Jiao YQ, Huang P, Yan L, Sun K, Pan CS, Li Q, et al. (2019). YangXue QingNao Wan, a Compound Chinese Medicine, Attenuates Cerebrovascular Hyperpermeability and Neuron Injury in Spontaneously Hypertensive Rat: Effect and Mechanism. Front Physiol, 10:1246.

[108] Shin JW, Kweon KJ, Kim DK, Kim P, Jeon TD, Maeng S, et al. (2018). Scutellarin Ameliorates Learning and Memory Deficit via Suppressing beta-Amyloid Formation and Microglial Activation in Rats with Chronic Cerebral Hypoperfusion. Am J Chin Med, 46:1203-1223.

[109] Impellizzeri D, Siracusa R, Cordaro M, Crupi R, Peritore AF, Gugliandolo E, et al. (2019). NPalmitoylethanolamine-oxazoline (PEA-OXA): A new therapeutic strategy to reduce neuroinflammation, oxidative stress associated to vascular dementia in an experimental model of repeated bilateral common carotid arteries occlusion. Neurobiol Dis, 125:77-91.

[110] Guo H, Callaway JB, Ting JP (2015). Inflammasomes: 
mechanism of action, role in disease, and therapeutics. Nat Med, 21:677-687.

[111] Du SQ, Wang XR, Zhu W, Ye Y, Yang JW, Ma SM, et al. (2018). Acupuncture inhibits TXNIP-associated oxidative stress and inflammation to attenuate cognitive impairment in vascular dementia rats. CNS Neurosci Ther, 24:39-46.

[112] Wang R, Yin YX, Mahmood Q, Wang XJ, Gao YP, Gou GJ, et al. (2017). Calmodulin inhibitor ameliorates cognitive dysfunction via inhibiting nitrosative stress and NLRP3 signaling in mice with bilateral carotid artery stenosis. CNS Neurosci Ther, 23:818-826

[113] Xia D, Sui R, Min L, Zhang L, Zhang Z (2019). Fastigial nucleus stimulation ameliorates cognitive impairment via modulating autophagy and inflammasomes activation in a rat model of vascular dementia. J Cell Biochem, 120:5108-5117.

[114] Franchi L, Eigenbrod T, Munoz-Planillo R, Nunez G (2009). The inflammasome: a caspase-1-activation platform that regulates immune responses and disease pathogenesis. Nat Immunol, 10:241-247.

[115] Daverey A, Agrawal SK (2020). Curcumin Protects against White Matter Injury through NF-kappaB and Nrf2 Cross Talk. J Neurotrauma.

[116] Yang MY, Yu QL, Huang YS, Yang G (2019). Neuroprotective effects of andrographolide derivative CX-10 in transient focal ischemia in rat: Involvement of Nrf2/AE and TLR/NF-kappaB signaling. Pharmacol Res, 144:227-234.

[117] Ranjbar Taklimie F, Gasterich N, Scheld M, Weiskirchen R, Beyer C, Clarner T, et al. (2019). Hypoxia Induces Astrocyte-Derived Lipocalin-2 in Ischemic Stroke. Int J Mol Sci, 20.

[118] Zhao N, Xu X, Jiang Y, Gao J, Wang F, Xu X, et al. (2019). Lipocalin-2 may produce damaging effect after cerebral ischemia by inducing astrocytes classical activation. J Neuroinflammation, 16:168.

[119] Lu YM, Han F, Shioda N, Moriguchi S, Shirasaki Y, Qin ZH, et al. (2009). Phenylephrine-induced cardiomyocyte injury is triggered by superoxide generation through uncoupled endothelial nitric-oxide synthase and ameliorated by 3-[2-[4-(3-chloro-2methylphenyl)-1-piperazinyl]ethyl]-5,6-

dimethoxyindazole (DY-9836), a novel calmodulin antagonist. Mol Pharmacol, 75:101-112.

[120] Hernandez-Jimenez M, Hurtado O, Cuartero MI, Ballesteros I, Moraga A, Pradillo JM, et al. (2013). Silent information regulator 1 protects the brain against cerebral ischemic damage. Stroke, 44:23332337.

[121] Yao P, Chen Y, Xu GH (2019). [Effect of triptolide on cognitive dysfunction in vascular dementia rats through SIRT1/NF-kappaB signaling pathway]. Zhongguo Zhong Yao Za Zhi, 44:3423-3428.

[122] Chen L, Zhang Y, Li D, Zhang N, Liu R, Han B, et al. (2016). Everolimus (RAD001) ameliorates vascular cognitive impairment by regulating microglial function via the mTORC1 signaling pathway. J Neuroimmunol, 299:164-171.
[123]

Lee KM, Bang J, Kim BY, Lee IS, Han JS, Hwang BY, et al. (2015). Fructus mume alleviates chronic cerebral hypoperfusion-induced white matter and hippocampal damage via inhibition of inflammation and downregulation of TLR4 and p38 MAPK signaling. BMC Complement Altern Med, 15:125.

[124] Kim MS, Bang JH, Lee J, Kim HW, Sung SH, Han JS, et al. (2015). Salvia miltiorrhiza extract protects white matter and the hippocampus from damage induced by chronic cerebral hypoperfusion in rats. BMC Complement Altern Med, 15:415.

[125] Sun M, Shen X, Ma Y (2019). Rehmannioside A attenuates cognitive deficits in rats with vascular dementia (VD) through suppressing oxidative stress, inflammation and apoptosis. Biomed Pharmacother, 120:109492.

[126] Zhao T, Fu Y, Sun H, Liu X (2018). Ligustrazine suppresses neuron apoptosis via the $\mathrm{Bax} / \mathrm{Bcl}-2$ and caspase-3 pathway in $\mathrm{PC} 12$ cells and in rats with vascular dementia. IUBMB Life, 70:60-70.

[127] Feng Z, Lu Y, Wu X, Zhao P, Li J, Peng B, et al. (2012). Ligustilide alleviates brain damage and improves cognitive function in rats of chronic cerebral hypoperfusion. J Ethnopharmacol, 144:313-321.

[128] Ji HJ, Hu JF, Wang YH, Chen XY, Zhou R, Chen NH (2010). Osthole improves chronic cerebral hypoperfusion induced cognitive deficits and neuronal damage in hippocampus. Eur J Pharmacol, 636:96-101. Zhang Y, Li Y, Wang Y, Wang G, Mao L, Zhang D, et al. (2019). Effects of resveratrol on learning and memory in rats with vascular dementia. Mol Med Rep, 20:4587-4593.

[130] Gupta S, Afaq F, Mukhtar H (2002). Involvement of nuclear factor-kappa $\mathrm{B}, \mathrm{Bax}$ and $\mathrm{Bcl}-2$ in induction of cell cycle arrest and apoptosis by apigenin in human prostate carcinoma cells. Oncogene, 21:3727-3738.

[131] Vogel MW (2002). Cell death, Bcl-2, Bax, and the cerebellum. Cerebellum, 1:277-287.

[132] Zhu JD, Wang JJ, Zhang XH, Yu Y, Kang ZS (2018). Panax ginseng extract attenuates neuronal injury and cognitive deficits in rats with vascular dementia induced by chronic cerebral hypoperfusion. Neural Regen Res, 13:664-672.

[133] Zhang XS, Sun JN, Yu HL (2015). [Effects of Total Alkaloids of Harmaline on Learning and Memory in Vascular Dementia Rats]. Zhong Yao Cai, 38:23532357.

[134] Hu L, Sun Y, Hu J (2010). Catalpol inhibits apoptosis in hydrogen peroxide-induced endothelium by activating the PI3K/Akt signaling pathway and modulating expression of $\mathrm{Bcl}-2$ and Bax. Eur $\mathrm{J}$ Pharmacol, 628:155-163.

[135] Xu XK, Wang SY, Chen Y, Zhan L, Shao ZY, Lin L, et al. (2018). Fangjing decoction relieves febrile seizures-induced hippocampal neuron apoptosis in rats via regulating the Akt/mTOR pathway. Biosci Rep, 38 .

[136] Zhang R, Zhu Y, Dong X, Liu B, Zhang N, Wang X, et al. (2017). Celastrol Attenuates Cadmium-Induced Neuronal Apoptosis via Inhibiting $\mathrm{Ca}(2+)$-CaMKIIDependent Akt/mTOR Pathway. J Cell Physiol, 
232:2145-2157.

[137] Peng Y, Sun J, Hon S, Nylander AN, Xia W, Feng Y, et al. (2010). L-3-n-butylphthalide improves cognitive impairment and reduces amyloid-beta in a transgenic model of Alzheimer's disease. J Neurosci, 30:81808189.

[138] Wang YG, Li Y, Wang CY, Ai JW, Dong XY, Huang HY, et al. (2014). L-3-n-Butylphthalide protects rats' cardiomyocytes from ischaemia/reperfusion-induced apoptosis by affecting the mitochondrial apoptosis pathway. Acta Physiol (Oxf), 210:524-533.

[139] Yang CS, Guo A, Li Y, Shi K, Shi FD, Li M (2019). Dl-3-n-butylphthalide Reduces Neurovascular Inflammation and Ischemic Brain Injury in Mice. Aging Dis, 10:964-976.

[140] Chen DP, Hou SH, Chen YG, Chen MS, Hu ZZ, Zhang ZJ (2018). L-butyl phthalein improves neural function of vascular dementia mice by regulating the PI3K/AKT signaling pathway. Eur Rev Med Pharmacol Sci, 22:5377-5384.

[141] Qi YY, Feng XF, Qiu L, Yang F (2019). 3-nbutylphthalide inhibits the apoptosis of nerve cells in rats with cerebral small vessel disease via the PI3K/Akt pathway. Eur Rev Med Pharmacol Sci, 23:4474-4480.

[142] Li W, Wei D, Lin J, Liang J, Xie X, Song K, et al. (2019). Dl-3-n-Butylphthalide Reduces Cognitive Impairment Induced by Chronic Cerebral Hypoperfusion Through GDNF/GFRalpha1/Ret Signaling Preventing Hippocampal Neuron Apoptosis. Front Cell Neurosci, 13:351.

[143] Tian A, Ma X, Li H, Zhang R (2020). Dl-3nbutylphthalide improves spatial learning and memory in rats with vascular dementia by reducing autophagy via regulation of the mTOR signaling pathway. Exp Ther Med, 19:1940-1946.

[144] Su SH, Wang YQ, Wu YF, Wang DP, Lin Q, Hai J (2016). Cannabinoid receptor agonist WIN55,212-2 and fatty acid amide hydrolase inhibitor URB597 may protect against cognitive impairment in rats of chronic cerebral hypoperfusion via PI3K/AKT signaling. Behav Brain Res, 313:334-344.

[145] Wang DP, Lv QL, Lin Q, Kang K, Jin KY, Hai J (2019). The Cannabinoid Receptor Agonist WIN55,212-2 Ameliorates Hippocampal Neuronal Damage After Chronic Cerebral Hypoperfusion Possibly Through Inhibiting Oxidative Stress and ASK1-p38 Signaling. Neurotox Res.

[146] Zhang Y, Wang LL, Wu Y, Wang N, Wang SM, Zhang B, et al. (2016). Paeoniflorin attenuates hippocampal damage in a rat model of vascular dementia. Exp Ther Med, 12:3729-3734.

[147] Li W, Liu H, Jiang H, Wang C, Guo Y, Sun Y, et al. (2017). (S)-Oxiracetam is the Active Ingredient in Oxiracetam that Alleviates the Cognitive Impairment Induced by Chronic Cerebral Hypoperfusion in Rats. Sci Rep, 7:10052.

[148] Xu J, Qi Q, Lv P, Dong Y, Jiang X, Liu Z (2019). Oxiracetam ameliorates cognitive deficits in vascular dementia rats by regulating the expression of neuronal apoptosis/autophagy-related genes associated with the activation of the Akt/mTOR signaling pathway. Braz J Med Biol Res, 52:e8371.

[149] Wang XL, Deng YX, Gao YM, Dong YT, Wang F, Guan ZZ, et al. (2020). Activation of alpha7 nAChR by PNU-282987 improves synaptic and cognitive functions through restoring the expression of synapticassociated proteins and the CaM-CaMKII-CREB signaling pathway. Aging (Albany NY), 12:543-570.

[150] Xiao LY, Wang XR, Yang JW, Ye Y, Zhu W, Cao Y, et al. (2018). Acupuncture Prevents the Impairment of Hippocampal LTP Through beta1-AR in Vascular Dementia Rats. Mol Neurobiol, 55:7677-7690.

[151] Dong J, Zhao J, Lin Y, Liang H, He X, Zheng X, et al. (2018). Exercise improves recognition memory and synaptic plasticity in the prefrontal cortex for rats modelling vascular dementia. Neurol Res, 40:68-77.

[152] Lisman J, Schulman H, Cline H (2002). The molecular basis of CaMKII function in synaptic and behavioural memory. Nat Rev Neurosci, 3:175-190.

[153] Hussain S, Ringsevjen H, Egbenya DL, Skjervold TL, Davanger S (2016). SNARE Protein Syntaxin-1 Colocalizes Closely with NMDA Receptor Subunit NR2B in Postsynaptic Spines in the Hippocampus. Front Mol Neurosci, 9:10.

[154] Bliss TV, Collingridge GL (1993). A synaptic model of memory: long-term potentiation in the hippocampus. Nature, 361:31-39.

[155] Yang J, Yao Y, Wang L, Yang C, Wang F, Guo J, et al. (2017). Gastrin-releasing peptide facilitates glutamatergic transmission in the hippocampus and effectively prevents vascular dementia induced cognitive and synaptic plasticity deficits. Exp Neurol, 287:75-83.

[156] Li W, Yuan H, Yu Y, Cheong YK, Ren G, Yang Z (2017). Etidronate rescues cognitive deficits through improving synaptic transmission and suppressing apoptosis in 2-vessel occlusion model rats. J Neurochem, 140:476-484.

[157] Li P, Zhu ML, Pan GP, Lu JX, Zhao FR, Jian X, et al. (2018). Vitamin B6 prevents isocarbophos-induced vascular dementia in rats through $\mathrm{N}$-methyl-Daspartate receptor signaling. Clin Exp Hypertens, 40:192-201.

[158] Li H, Wang J, Wang P, Rao Y, Chen L (2016). Resveratrol Reverses the Synaptic Plasticity Deficits in a Chronic Cerebral Hypoperfusion Rat Model. J Stroke Cerebrovasc Dis, 25:122-128.

[159] Liu Z, Hu M, Lu P, Wang H, Qi Q, Xu J, et al. (2017). Cerebrolysin alleviates cognitive deficits induced by chronic cerebral hypoperfusion by increasing the levels of plasticity-related proteins and decreasing the levels of apoptosis-related proteins in the rat hippocampus. Neurosci Lett, 651:72-78.

[160] Lu B, Nagappan G, Guan X, Nathan PJ, Wren P (2013). BDNF-based synaptic repair as a disease-modifying strategy for neurodegenerative diseases. Nat Rev Neurosci, 14:401-416.

[161] Bai Y, Lu P, Han C, Yu C, Chen M, He F, et al. (2012). Hydroxysafflor yellow A (HSYA) from flowers of 
Carthamus tinctorius L. and its vasodilatation effects on pulmonary artery. Molecules, 17:14918-14927.

[162] Xing M, Sun Q, Wang Y, Cheng Y, Zhang N (2016). Hydroxysafflor yellow A increases BDNF and
NMDARs in the hippocampus in a vascular dementia rat model. Brain Res, 1642:419-425. 